\title{
The mirroring hypothesis: theory, evidence, and exceptions
}

\section{Citation}

Colfer, Lyra J., and Carliss Y. Baldwin. 2016. “The Mirroring Hypothesis: Theory, Evidence, and Exceptions." Industrial and Corporate Change 25 (5) (September 15): 709-738. doi:10.1093/icc/ dtw027.

\section{Published Version}

https://doi.org/10.1093/icc/dtw027

\section{Permanent link}

http://nrs.harvard.edu/urn-3:HUL.InstRepos:33785675

\section{Terms of Use}

This article was downloaded from Harvard University's DASH repository, and is made available under the terms and conditions applicable to Other Posted Material, as set forth at http:// nrs.harvard.edu/urn-3:HUL.InstRepos:dash.current.terms-of-use\#LAA

\section{Share Your Story}

The Harvard community has made this article openly available.

Please share how this access benefits you. Submit a story.

\section{Accessibility}




\title{
The mirroring hypothesis: theory, evidence, and exceptions
}

\section{Lyra J. Colfer and Carliss Y. Baldwin*}

Broadway Technology, 5000 Plaza on the Lake, Austin, TX 78746, USA. e-mail: Icolfer@broadwaytechnology.com and Harvard Business School, Baker Library 341, Boston, MA 02163, USA. e-mail: cbaldwin@hbs.edu

*Main author for correspondence.

\begin{abstract}
The mirroring hypothesis predicts that organizational ties within a project, firm, or group of firms (e.g., communication, collocation, employment) will correspond to the technical dependencies in the work being performed. This article presents a unified picture of mirroring in terms of theory, evidence, and exceptions. First, we formally define mirroring and argue that it is an approach to technical problem-solving that conserves scarce cognitive resources. We then review 142 empirical studies, divided by organizational form into (i) industry studies, (ii) firm studies, and (iii) studies of open collaborative projects. The industry and firm studies indicate that mirroring is a prevalent pattern but not universal. However, in technologically dynamic industries, partial mirroring, where knowledge boundaries are drawn more broadly than operational boundaries, is likely to be a superior strategy. Firms can also strategically 'break the mirror' by implementing modular partitions within their boundaries, or by building relational contracts across their boundaries. Finally, studies of open collaborative projects, most of which focused on software, were not supportive of the hypothesis. We argue that digital technologies make possible new modes of coordination that enable groups to deviate from classical mirroring as seen in firms.
\end{abstract}

JEL classification: D23, D85, L22, 032

\section{Introduction}

Innovation is a process in which people define problems and then actively develop new knowledge to solve them (Nonaka, 1994). In the modern economy, much new knowledge takes the form of new product and process designs. Modern efforts to develop new designs in turn require the coordination of an ever wider range of disciplines, embodied in complex technical systems and processes (Brusoni et al., 2001).

Given the well-known challenges of coordinating complex interdependent tasks (e.g., Thompson, 1967: Galbraith, 1974), theorists have tended to predict (or recommend) that the formal structure of an organization will (or should) "mirror" the design of the underlying technical system (e.g., Conway, 1968; Henderson and Clark, 1990; von Hippel, 1990; Chesbrough and Teece, 1996; Sanchez and Mahoney 1996; Baldwin and Clark, 2000). These theories in turn lead to empirically testable predictions: the organizational ties in a project, firm, or group of firms (e.g., communication, collocation, employment relations) will (or should) correspond to the technical dependencies in the work being performed. 
This basic idea has different names in different fields. In organization design, it can be seen as an application of task contingency theory to complex technical systems (Lawrence and Lorsch, 1967; Thompson, 1967; Galbraith, 1974; Tushman, 1979; Drazin and Van deVen, 1985; Tushman and Nadler, 1978). In computer science, it is known as Conway's Law (Conway, 1968). Notably, the hypothesis predicts correspondence but does not impose a direction of causality: effects may flow from organizational structure to technical design (Henderson and Clark, 1990); from technical design to organizational structure (Chandler, 1977); or in both directions (Baldwin and Clark, 2000; Fixson and Park, 2008).

A thorough understanding of the evidence for and against the mirroring hypothesis is difficult to achieve. The relevant literature is scattered across a number of fields in management, economics, and engineering, and there are significant differences in how the hypothesis is interpreted in the different streams of literature. This article seeks to present a unified picture of the mirroring hypothesis in terms of theory, evidence, and exceptions. Accordingly, this study makes two contributions. First, it formally defines the mirroring hypothesis and systematically reviews and summarizes the empirical evidence pertaining to it. Second, it synthesizes observations from a wide range of studies to describe the boundary conditions of mirroring, that is, when and why mirroring is likely to be an effective strategy vs. when and why organizations can benefit by 'breaking the mirror' partially or wholly. ${ }^{1}$

Our analysis proceeds as follows. First, we trace the intellectual roots of the mirroring hypothesis, formally define it in terms of network graphs, and work out its descriptive and normative implications. We argue that the mirroring of technical dependencies and organizational ties is an approach to organizational problem-solving that conserves scarce cognitive resources.

Building on this theoretical base, we then systematically review the empirical evidence pertaining to the hypothesis. We consider 142 empirical studies, most of which were published between 2000 and 2015. The studies were categorized according to whether they were primarily descriptive (seeking to establish relationships between technical dependencies and organizational ties) or normative (considering the performance of mirrored or unmirrored organizations) and further divided by organizational form into (i) industry studies, (ii) firm studies, and (iii) studies of open collaborative projects. We then classified each study according to whether its results fully or partially supported or failed to support the mirroring hypothesis.

The industry and firm studies showed that correlation between technical interdependencies and organizational ties is a common pattern both cross-sectionally and over time. Over two-thirds $(70 \%)$ of the descriptive studies provide strong evidence of mirroring, $22 \%$ provide partial support, while only $8 \%$ do not support the hypothesis. The normative studies of firms provide a more nuanced view of the phenomenon. In particular, they reveal the existence of a mirroring 'trap': firms focused on the current technical architecture may fall victim to architectural innovations arising outside their boundaries. Thus, in technologically dynamic industries, partial mirroring, where knowledge boundaries are drawn more broadly than operational boundaries, is likely to be a superior strategy. Furthermore, it is possible for firms to strategically 'break the mirror' in two ways: first, by implementing modular partitions within their own boundaries; and second, by building relational contracts that support high levels of technical interdependency across their boundaries. Strategic mirror-breaking can be a source of competitive advantage and over time can change the structure of industries.

The evidence from open collaborative projects (a relatively new form of organization) paints a very different picture. Here the majority of descriptive studies $(56 \%)$ do not support the mirroring hypothesis, while normative studies are too few in number to be decisive. We will argue that these contradictory results arise because digital technologies make possible new modes of coordination that enable groups to deviate from classical mirroring as seen within firms.

Section 2 presents the theory behind the mirroring hypothesis and formulates it in descriptive and normative terms. Section 3 describes our sample and methods of analysis. Section 4 presents an overview of our results. (Our detailed findings are summarized in two Supplementary Appendices.) Sections 5-7 describe themes that cut across descriptive and normative formulations. Section 8 summarizes our findings, describes boundary conditions, and concludes.

1 Throughout the article, we place single quotation marks around terms we use as metaphors and double quotation marks around direct quotes from the work of others. 


\section{What is the mirroring hypothesis?}

The management literature that pertains to the mirroring hypothesis commonly draws on two distinct sources for its motivation: (i) the literature on organization design and organizations as complex systems (e.g., Thompson, 1967; Galbraith, 1974; Weick, 1976); and (ii) the literature on product design and products as complex systems (e.g., Alexander, 1964; Parnas, 1972, 1978; Ulrich, 1995). A separate tradition in computer science builds upon "Conway's Law," which states that "organizations which design systems ... are constrained to produce designs which are copies of the communication structures of these organizations" (Conway, 1968: 31). All three traditions make use of the concept of modularity.

Scholars in the organization-design tradition usually attribute the concept of modularity to Herbert Simon (1962, 1981), who used the parable of Hora and Tempus to illustrate the advantage of partitioning a complex problem into parsimoniously linked sub-problems:

Hora ... put together subassemblies of about ten elements each. ... Hence, when Hora had to put down a partly assembled watch... he lost only a small part of his work, and he assembled his watches in only a fraction of the man-hours it took Tempus. (Simon, 1981: 188)

By partitioning the watch into modular subassemblies, Hora made it easier to cope with the complexity of creating a watch. Thompson (1967) went on to argue that, to achieve efficiency in the face of underlying complexity, organizations should place "reciprocally interdependent" tasks within a common organizational group.

Scholars in the product-design and computer science traditions take inspiration from Simon, but also refer to works by Alexander (1964) and Parnas $(1972,1978)$. Like Simon, Alexander (1964) argued that it is easier to cope with the complexity of a large-scale problem if it is decomposed into parsimoniously linked sub-problems. Parnas $(1972,1978)$ argued that it is easier to split development work across a group if people can work independently and in parallel. To support parallelism, Parnas encouraged developers to avoid sharing assumptions and data. Specifically, he contended that every developer's task assignment should lie within a product module that is "characterized by its knowledge of a design decision that it hides from all others" (1972: 1056).

Information hiding as a means of controlling complexity is a fundamental principle underlying the mirroring hypothesis. With information hiding, each module in a technical system is informationally isolated from other modules within a framework of system design rules. This means that independent individuals, teams, or firms can work separately on different modules, yet the modules will work together as a whole (Baldwin and Clark, 2000). As a result, there will be a mapping ${ }^{2}$ from technical modules to designers or design teams (Conway, 1968; Parnas, 1972, 1978). This mapping allows the mirroring hypothesis to be formally stated in terms of a structural correspondence between two networks, one technical and one organizational.

\subsection{Formal definition}

Following Simon (1981), we define the elementary components of a technical system as a set of decisions and/or tasks. If the system is a design, the tasks are decisions about design parameters (Baldwin and Clark, 2000). However, more broadly, the components of a technical system include all the tasks and decisions required to design, operate, and maintain the system (Baldwin, 2008; Arthur, 2009; Puranam et al., 2012). Examples of technical systems include complex products and services, large software systems, manufacturing processes, supply chains, systems for transport and logistics, military systems, the electrical grid, telecommunication networks, and the Internet. Technical systems are often combined to make larger systems as when a handset, software, and the telecommunication network are combined to create the functionality of a mobile phone (Arthur, 2009).

The technical architecture of a system captures "what depends on what" as determined by the underlying technology. It is the scheme by which the technical system's functions and sub-functions are allocated to distinct components (nodes in a network), plus a description of the technical dependencies (links) between components (Ulrich, 1995; Baldwin and Clark, 2000; Whitney et al., 2004). Technical dependencies are relationships of the form "if something in Component 1 changes, then Component 2 may need to change as well” (Parnas 1972, 1978; Baldwin and Clark, 2000).

2 The mapping is not one-to-one because a single designer or team may have responsibility for several modules. However, each module will have only one designer or design team (Conway, 1968, p. 30). 


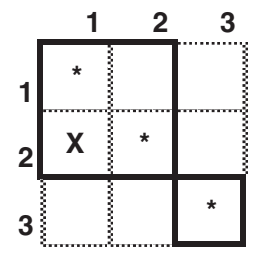

Figure 1. A technical dependency matrix.

The division of labor captures "who does what." It is the scheme by which the tasks in the technical architecture are assigned to people or teams (nodes) who will perform the tasks plus the organizational ties, such as communication channels, geographic collocation, or employment relations, that link those people. ${ }^{3}$ The mirroring hypothesis posits that, in a complex system, ${ }^{4}$ the technical architecture and the division of labor will "mirror" one another in the sense that the network structure of one will correspond to the structure of the other. To visualize what this means, we can represent the technical and organizational networks using matrices.

For the technical architecture, a technical dependency matrix ${ }^{5}$ shows the network of dependencies among the technical components or tasks. For example, Figure 1 depicts a technical system with three tasks such that Task 2 depends on Task 1 , and there are no other dependencies. The single dependency is recognized by placing an " $\mathrm{x}$ " in the column of Task 1 and the row of Task 2. The heavy lines in the figure group the tasks according to their dependencies.

The technical dependency matrix does not describe the division of labor nor methods of coordination. We introduce the organizational ties matrix for this purpose. This matrix is constructed by first associating a person or team with each task and labeling each cell on the main diagonal accordingly. For example, for the system depicted in Figure 1, suppose Alice is given Task 1 , Bob is given Task 2, and Carol is given Task 3 . In a separate $3 \times 3$ matrix with similar rows and columns, we place the uppercase letters $\mathrm{A}, \mathrm{B}$, and $\mathrm{C}$ along the main diagonal as shown in Figure 2. These assignments indicate which agents have primary responsibility and knowledge about each task. The mirroring hypothesis predicts that, given the dependency between their tasks, Bob and Alice will share one or more explicit organizational ties that enable them to coordinate their actions. We denote the (presumptive) presence of an organizational tie between Alice and Bob, by placing the notation “ab" in Alice's column and Bob's row. By comparison, Carol shares no task dependencies with Alice or Bob; thus, the mirroring hypothesis predicts no organizational ties for her. More generally, the mirroring hypothesis predicts that the technical dependency matrix and organizational ties matrix will have entries in the same cells. The structure of one will correspond to the structure of the other, as can be seen by overlaying Figure 2 on Figure 1.

What constitutes an organizational tie? Early theorists such as Simon (1962), Thompson (1967), and Conway (1968) mainly focused on communication links between people. However, actual communication is often transient and thus difficult to observe (Bucciarelli, 1994). Collocation of individuals is known to facilitate communication (Allen, 1984), and hence, it often serves as a proxy for the existence of a communication channel. Additionally, full coordination may require not only communication, but also cooperation and/or efficient methods of settling disputes (Williamson, 1975, 1991; Gulati et al., 2005; Jacobides, 2006). People employed by the same organization may be more disposed to cooperate and are embedded in management hierarchies capable of making expeditious decisions. Thus, employment by the same firm is a third form of organizational tie, which can positively affect coordination of technical dependencies.

3 Tasks may be assigned to machines, but we are concerned with linkages between people. Thus we would define machine tending or management as person's task and look for organizational ties between people.

4 As discussed below, mirroring is basically a strategy for conserving cognitive resources of individuals and organizations. Simple systems are easily comprehended, thus do not need to be mirrored.

5 Technical dependency matrices are often called Design Structure Matrices or DSMs (Baldwin and Clark, 2000; Steward, 1981; Eppinger, 1991). 


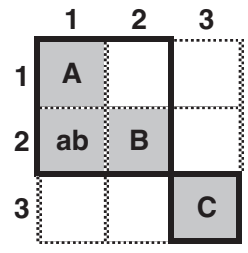

Figure 2. An organizational ties matrix (corresponding to the previous technical dependency matrix).

\subsection{Mirroring as an approach to problem-solving}

The mirroring of technical dependencies and organizational ties can be explained as an approach to organizational problem-solving that conserves scarce cognitive resources. People charged with implementing complex projects or processes are inevitably faced with interdependencies that create technical problems and conflicts in real time. They must arrive at solutions that take account of the technical constraints; hence, they must communicate with one another and cooperate to solve their problems. Communication channels, collocation, and employment relations are organizational ties that support communication and cooperation between individuals, and thus, we should expect to see a very close relationship-technically a homomorphism-between a network graph of technical dependencies within a complex system and network graphs of organizational ties showing communication channels, collocation, and employment relations. This in turn means that organizational ties will be dense within modules of the system where technical dependencies are dense and sparse across modules where technical dependencies by definition are sparse (Baldwin and Clark, 2000).

Aligning organizational ties with technical dependencies is an economical way to manage complex technical systems that require human coordination in real time. Notably, such alignment does not have to be a conscious choice by any one person or group, but can arise through an evolutionary process of decentralized problem solving (Alchian and Demsetz, 1972; Nelson and Winter, 1982). That is, the people charged with managing a complex technical system will create and/or eliminate technical dependencies and organizational ties where and when needs arise. If needs persist, the association between technical dependencies and organizational ties will also persist and the correlation will be observable.

Henderson and Clark (1990) were among the first to recognize that mirroring can arise through invisible organizational processes. They noted that "organizations are boundedly rational and, hence, $\ldots$ their knowledge and information processing structure come to mirror the internal structure of the product they are designing" (p. 27). They also found that mirroring could have negative consequences for performance, an issue we shall return to below.

Nickerson and Zenger (2004) viewed organizations as problem-solving entities, but saw the basic problem as opportunism, not complexity per se. They argued that solving complex problems with many interdependencies requires knowledge sharing (communication) among agents, but such exchanges are subject to opportunistic hazards in the form of appropriation (stealing) and accumulation (hoarding). Markets have a low capacity for remedying these hazards; thus, complex problems are best addressed within hierarchies, that is, by firms. Their reasoning implies that complex problems with many interdependencies will (or should) be addressed by agents with at least two organizational ties-communication links that permit knowledge exchange and employment by the same firm to dampen opportunistic behavior.

Puranam et al. (2012) advanced the theory of organization design by pointing out that there are different types of interdependence between technical components of a system. Information exchanges are valuable when one agent needs to predict another's action to choose his or her own best course. Such "epistemic" interdependence requires coordination, hence communication in near real time. Below, when we speak of technical interdependence, we specifically refer to epistemic interdependence. Epistemic interdependence creates a need for coordination, which is in turn facilitated by organizational ties.

\subsection{Origins of the mirroring hypothesis}

Different versions of the mirroring hypothesis were derived independently by James Thompson and Melvyn Conway at approximately the same time. There is no evidence that they knew about each other. 
Building on Simon (1957), Thompson (1967) argued that, given bounded rationality, actors performing technologically interdependent tasks should be collocated and communicate more with each other than with actors outside their group. Furthermore, when interdependence is extensive so as to "overtax communication mechanisms," the organization should rank order the degree of interdependency among actors, let those with the greatest interdependency form a group, and cluster the smaller groups into "an overarching second-order group" (p. 59).

This method of clustering implicitly forms a hierarchy. Thompson went on to say that "if we assume that the probability of conflict among [actors] or groups is directly proportional to their degree of interdependence," then this hierarchical structure can serve as a device for the resolution of conflicts (ibid. p. 60). Thus, actors performing interdependent tasks should have the organizational ties of collocation, communication linkage, and a common dispute-resolution mechanism. The need for such ties increases as technical interdependency rises.

This is the mirroring hypothesis, with causal effects running from technical dependencies to organizational ties.

Conway (1968) focused on the process of designing a complex system. Before the design process can start, he noted, there must be a provisional partitioning of the system into subsystems and components. On the basis of that preliminary idea, task groups are formed and activities delegated to those groups. Within the task groups there will be many communication links, while across groups there will be few or none at all.

Conway argued that, for there to be a dependency between two components of the larger system, the designers of those components must have previously negotiated and agreed upon an interface specification, because technical components generally do not work together by pure chance. Thus, the presence of a working technical dependency is evidence of prior communication and cooperation, that is, organizational ties, between the designers. Conversely, if there is no communication and cooperation between designers, there can be no effective dependencies between their components (although there may be latent dependencies that cause the system to break down).

In other words, the existence of organizational ties can affect the placement of technical dependencies and thus influence the technical architecture of the system under development. This conjecture became known as Conway's Law: "organizations which design systems ... are constrained to produce designs which are copies of [their] communication structures." (ibid.p. 31).

This is also the mirroring hypothesis, but with causal effects running from organizational ties to technical dependencies.

There is a tendency among management scholars to view technical dependencies as facts of nature and organizational ties as targets of design. There is a symmetric tendency among engineers and product developers to view the technical system as malleable while organizational ties are fixed by precedent, routines, and decisions made higher up the chain. In fact, both technical dependencies and organizational ties can be changed albeit at some cost. Furthermore, a competitive market economy will reward those combinations of technical architecture and organizational structure that deliver the greatest value at the least cost.

\subsection{Mirroring across firms}

The mirroring hypothesis entered the strategy literature via seminal works by Langlois and Robertson (1992) and Sanchez and Mahoney (1996). The key insight was that the absence of technical and organizational ties might determine or predict the location of firm boundaries. Thus, technical systems made up of many discrete modules can be implemented by loosely coupled organizations, i.e., separate firms, while systems with many interdependencies require tighter coupling such as is found in a single firm. Confirming this possibility, Baldwin and Clark (2000) described the vertical disintegration of the computer industry following the introduction of System/360, the first modular computer system. They observed that the arrival of a new modular product architecture provides opportunities for entry by specialized module makers.

Langlois (2002) then made the case that firms are non-modular structures with ambiguous internal boundaries that facilitate "communication of rich information" (p. 34). Baldwin (2008) went on to argue that transaction costs are low at module boundaries and high in module interiors; thus, by the logic of transaction cost economics (Williamson, 1985), the boundaries of firms should correspond to the boundaries of the underlying technical modules. These arguments were placed in a dynamic context by Wolter and Veloso (2008) who pointed out that obsolescence risk and the need to preserve outside options create forces causing fragmentation, and therefore firms and industries experiencing modular or radical innovations may have a propensity to break apart. Thus, from a dynamic 
perspective, "modularization as a process" (cf. MacDuffie, 2013) may underlie changes in industry and organizational structure, a possibility we explore in Section 5 below.

An important caveat to the mirroring hypothesis arises with regard to technical knowledge. Recall that information hiding is a key justification for the creation of modules. People working in one part of a modular system can focus on tasks related to their module and do not need to know what is happening in other modules. This partitioning of knowledge reduces the amount of knowledge needed by any one person or group, and thus is a valuable attribute in any system that depends on boundedly rational individuals. Following the logic of information hiding, a simple version of the mirroring hypothesis would predict that knowledge, like tasks, would be divided up in accordance with the modular structure of the underlying technical system.

This simple view has been challenged by a stream of work on system integration initiated by Brusoni et al. (2001) and Brusoni and Prencipe (2001). Observing the design and construction of complex technical systems involving many firms, they found that whereas the systems were modular (and mirrored) with respect to technical dependencies and most tasks, the systems integrator had to interactively coordinate and manage the entire network of component suppliers. To fulfil this coordination role, systems integrators needed capabilities that spanned a wide range of technical fields. As a result, their knowledge extended well beyond what was directly relevant to the tasks they performed in-house. Thus, a simple version of the mirroring hypothesis, based on strict information hiding, must be qualified in the case of the knowledge of systems integrators. Such firms "know more than they make" (Brusoni et al., 2001: 597).

Indeed this observation applies to any firm that seeks competitive advantage through strategic manipulation of its boundaries and surrounding "industry architecture" (Jacobides, 2006). Managers can influence what an organization learns, and thus affect a firm's future capabilities and ability to adapt (Teece et al., 1997; Jacobides and Winter, 2012). Overly strict mirroring of knowledge with task dependencies is likely to prevent a firm from seeing opportunities to change its boundaries and/or restructure its industry. Thus, while mirroring conserves scarce cognitive resources, hence is efficient in the short run, strict mirroring can be a trap. Instead, in technologically dynamic industries, firms must scan both new technologies and current contracting arrangements to identify "bottlenecks" that may be controlled by changing technical dependencies and organizational ties to create new institutional arrangements (Jacobides et al., 2006; Pisano and Teece, 2007; Baldwin, 2015).

Viewed over time, technical and organizational architectures can be seen as dynamically changing and a source of strategic opportunity. However, such changes do not take place in a vacuum. MacDuffie (2013) has argued that modularity is not a simple property that can be changed via managerial fiat, but instead is the result of a learning process that involves "mapping functions to components ... and then setting out to learn and master the remaining interdependencies ... to make sure that interfaces can accommodate them" (p. 11). Baldwin and Clark (2000) describe this micro-process as one involving knowledge accumulation followed by purposeful information hiding. Designers must first map technical dependencies and determine their causes, then selectively eliminate interdependencies through the creation of design rules governing architecture, interfaces, and tests. "Modularization as a process" is lengthy and arduous, but it cannot be set aside. Premature modularization misses latent interdependencies, which detract from performance and may cause the system to fail entirely.

\subsection{Descriptive and normative versions of the hypothesis}

The mirroring hypothesis contends that there exists a correspondence (homomorphism) between the network of technical dependencies between tasks and the network of organizational ties between the people performing the tasks. From a research perspective, the hypothesis can be approached as either a descriptive prediction or a normative recommendation. From a descriptive standpoint, the hypothesis predicts a correlation between technical dependencies and organizational ties. From a normative standpoint, the hypothesis can be taken as a recommendation regarding the best way to set up a technical system and corresponding organization. In the next sections, we explain how these different points of view lead to different empirically testable hypotheses.

\subsection{Mirroring as a descriptive hypothesis}

Empirical researchers who approach the mirroring hypothesis in a descriptive fashion generally do not presume that any agent had the strategic intent to create a mirrored or unmirrored system. Often they are agnostic as to whether mirroring is likely to enhance or detract from an organization's performance. These researchers seek instead to 
establish the presence or absence of mirroring as a descriptive fact, by looking at correlations between technical dependencies and organizational ties in cross-section or over time. Implicitly or explicitly, they test the following hypothesis:

H1: In a complex technical system, organizational ties are more likely to exist in places where technical interdependencies are present (or dense). Organizational ties are likely to be absent where technical interdependencies are absent (or sparse).

To test the descriptive form of the mirroring hypothesis, researchers must collect data on the dependencies between technical components and separately collect data on task assignments, organizational ties, and firm boundaries. They can then look to see whether organizational ties are correlated with the presence of technical dependencies. High correlation is evidence in favor of the descriptive hypothesis: low or no correlation is evidence against it.

Within and across firms, the three main types of organizational ties themselves tend to be correlated. Communication is easier within teams and within firms than across teams or firms (King, 1999; Kleinbaum et al., 2008). Employees of the same firm are often geographically collocated, and collocation itself makes communication easier. Thus, the presence of one organizational tie may be a proxy for others within and across firms.

\subsection{Mirroring as a normative hypothesis}

Complex technical systems and organizations are man-made systems. Their structures can arise through an evolutionary process as described above, but they are also targets of design (Baldwin and Clark, 2000; Jacobides, 2006; Puranam et al., 2014). The designers of technical systems are boundedly rational-they cannot know or do everything. Thus, organizations are needed to carry out complex design and production processes. For system architects and organization designers, the design challenge is to create a technical architecture and corresponding organization that together are capable of carrying out complex tasks and solving problems that may come up along the way.

A mirrored system, we have seen, is an economical way to set up a complex technical system. It places problemsolving resources where problems are most likely to appear. Thus, architects and managers may consciously want to create mirrored organizations. And, if their conjectures are correct, mirrored organizations will perform well, and unmirrored organizations will perform poorly.

However, mirroring is only one design option. In some cases, a strictly mirrored system may preclude firms from anticipating or pursuing architectural innovations. In other cases, it may be prohibitively costly or logistically infeasible. Thus, architects and managers may trade-off the economy of strict mirroring in favor of other benefits or in response to organizational limitations and constraints. They may consciously seek to create partially mirrored systems or even unmirrored systems.

Empirical researchers approaching the mirroring hypothesis from a normative perspective assume that some designer or team intended to create a mirrored or unmirrored system. They then correlate the system designmirrored, partially mirrored, or unmirrored-with one or more measures of system performance. Implicitly or explicitly, they test the following hypothesis:

H2: Mirrored systems achieve good performance outcomes, and unmirrored systems achieve poor performance outcomes.

To test this version of the hypothesis, researchers must first collect data on the extent of mirroring in a given system and then evaluate the performance of the organization. High rates of success for mirrored systems and/or low rates of success for unmirrored systems are evidence for the hypothesis; the converse patterns are evidence against the hypothesis.

We now move on to review the empirical evidence on mirroring from both a descriptive and normative perspective.

\section{Empirical evidence on the mirroring hypothesis: data and methods}

In this and the following sections, we report the results of a survey and synthesis of the empirical evidence pertaining to the mirroring hypothesis. We first describe how we obtained and analyzed our sample. We then present an overview of the results. Detailed findings are given in Supplementary Appendix A. A tabular description of the data is presented in Supplementary Appendix B. Works in the sample are listed separately in the References section of this article. 
We were able to identify 142 separate studies, in a wide range of settings, in which both technical dependencies and organizational ties were observed and their correspondence assessed in a rigorous quantitative or qualitative fashion. The studies were divided into two groups: an extensive compilation of 103 studies published before and during 2009 and a supplementary compilation of 39 studies published since then. We used the supplementary group as a means of checking on the validity of our framework and identifying new trends.

In our sample of 142 studies, just under half (68) took a descriptive stance, looking at correlations between technical dependencies and organizational ties either in cross-section or over time. Slightly over half (74) took a normative stance and evaluated the success and/or failure of mirrored and unmirrored systems. Each study constitutes an observation of a case in which the descriptive or normative version of the mirroring hypothesis might or might not hold. We believe it is worthwhile to examine this evidence critically, summarize it statistically, and identify commonalities and differences among the separate studies.

\subsection{Sample selection}

We began in 2009 by conducting an electronic search for relevant scholarly works across the full digital publication lives of 19 major journals spanning multiple disciplines. These journals are listed in Table 1. To cast a wider net for the nascent literature on open collaborative projects, we repeated the search using the Association of Computer Machinery (ACM) Portal's Guide to Computing Literature. We used a broad set of keywords to perform the search: these appear in Table 2.

We examined titles and descriptions of the search results to remove duplicates, bibliographies, editors' commentaries, book reviews, pure theory works, directions for future research, experiments and simulations, technical "white papers" and unrelated articles. We then examined the abstracts of the 141 remaining candidates and removed another 35 due to lack of direct relevance (e.g., the article investigated technical architecture or organizational structure but not both). After this initial filtering, we expanded the sample in two ways. First, in a snowball type search, we scanned the retained articles for relevant studies that were not yet included. We also added studies with which we were familiar. We reviewed the full contents of the 130 studies in the resulting set. We found that 27 did not have sufficient data to correlate technical dependencies with organizational ties, and dropped these from the sample.

In 2015, we undertook a second snowball search aimed at capturing salient works published since 2009. We identified 59 potentially relevant studies, applied the same screens as in the initial sample, and obtained 39 studies that met our criteria for inclusion. We first analyzed the two groups separately and then checked to see if the results were similar. On the whole, we found the results to be consistent, and thus we felt comfortable pooling the two samples.

The resulting sample included 146 articles and books, but only 142 separately classified studies, since some works contained more than one study and others contained duplicate discussions of the same study. Of these, 140 were reported in scholarly works; two were reported in books describing the personal experiences of the chief architect of a development project (Mead and Conway, 1980; Colwell, 2005). We believe the two studies based on personal experience constitute valid empirical observations, but our results would not be significantly affected by their exclusion. Although large, the sample is not exhaustive: some relevant studies undoubtedly escaped our net. Nevertheless, the sample is broad-based and (we believe) representative of scholarly empirical work through the middle of 2015 .

Table 1. Journals included in the initial search for empirical evidence

\begin{tabular}{ll}
\hline Academy of Management Journal & Journal of Management Studies \\
\hline Academy of Management Review & Journal of Product Innovation Management \\
Administrative Science Quarterly & Management Science \\
California Management Review & Managerial and Decision Economics \\
Harvard Business Review & Organization Science \\
IEEE Engineering Management Review & Organization Studies \\
IEEE Software & Research in Engineering Design \\
IEEE Transactions on Engineering Management & Research Policy \\
Industrial and Corporate Change & Strategic Management Journal \\
Industry and Innovation &
\end{tabular}


Table 2. The keyword string used in the initial search for empirical evidence

((modular OR modularity OR “product architecture”) AND “division of labor”) OR

((modular OR modularity OR "product architecture”) AND “organizational structure”) OR

((modular OR modularity OR "product architecture”) AND “industry structure”) OR

((modular OR modularity) AND “open source”) OR “task partitioning”

Table 3. Breakdown of studies in the core sample by industry and year of publication

\begin{tabular}{|c|c|c|c|c|c|c|c|c|c|c|}
\hline All studies & $\begin{array}{l}\text { Before } \\
2000\end{array}$ & $\begin{array}{l}2000- \\
2001\end{array}$ & $\begin{array}{l}2002- \\
2003\end{array}$ & $\begin{array}{l}2004 \\
2005\end{array}$ & $\begin{array}{l}2006- \\
2007\end{array}$ & $\begin{array}{l}2008- \\
2009\end{array}$ & $\begin{array}{l}2010- \\
2011\end{array}$ & $\begin{array}{l}2012- \\
2013\end{array}$ & $\begin{array}{l}2014- \\
2015\end{array}$ & Total \\
\hline \multicolumn{11}{|l|}{ Information-based industries } \\
\hline Software & 3 & 2 & 5 & 6 & 8 & 6 & 2 & 4 & 3 & 39 \\
\hline Digital media & & & & & & 1 & & & & 1 \\
\hline Semiconductors & 4 & & 2 & & 5 & 1 & & 2 & 1 & 15 \\
\hline Computers & 2 & 3 & 1 & & 1 & 2 & 1 & & 2 & 12 \\
\hline Telecommunication & & & 2 & & & & & & & 2 \\
\hline IT support & & & & 1 & & & 1 & & & 2 \\
\hline Diverse IT & & & & 1 & & & & & & 1 \\
\hline Total & 9 & 5 & 10 & 8 & 14 & 10 & 4 & 6 & 6 & 72 \\
\hline \multicolumn{11}{|l|}{ Manufacturing industries } \\
\hline Autos & 2 & 3 & 1 & 2 & 4 & 1 & & 5 & 1 & 19 \\
\hline Aircraft and defense & 2 & 2 & & 1 & 1 & 2 & 1 & 1 & 1 & 11 \\
\hline Chemical & & & & 1 & 1 & & & & & 2 \\
\hline Steel & & & & & 1 & & & & & 1 \\
\hline Metals & & & & & & 1 & & & & 1 \\
\hline Manufacturing equipment & 1 & & & 1 & & & & 1 & & 3 \\
\hline Air conditioning & & & & & & & & & 1 & 1 \\
\hline Sci instruments & & & & & & 1 & & & 1 & 2 \\
\hline Home appliances & & & 1 & & & & & & & 1 \\
\hline Power tools & 1 & & & & & & & & & 1 \\
\hline Cameras & & & & & & 1 & & & & 1 \\
\hline Sports and games & & 1 & & & 2 & 1 & 1 & & & 5 \\
\hline Stereos & 2 & & & & & & & & & 2 \\
\hline Clothing & & & & & 1 & & & & & 1 \\
\hline Food & & & & & & & & & 1 & 1 \\
\hline Pharmaceuticals & & & & & & & & 1 & & 1 \\
\hline Diverse Manufacturing & 2 & & & 1 & 1 & 1 & & 3 & 2 & 10 \\
\hline Total & 10 & 6 & 2 & 6 & 11 & 8 & 2 & 11 & 7 & 63 \\
\hline \multicolumn{11}{|l|}{ Other industries } \\
\hline Banking & & & & 1 & & 1 & & & & 2 \\
\hline Construction & 1 & & & 1 & & & 2 & & 1 & 5 \\
\hline Healthcare & & & & & & & & 1 & & 1 \\
\hline Professional services & & & & & & & & & 1 & 1 \\
\hline Total & 1 & 0 & 0 & 2 & 0 & 1 & 2 & 1 & 2 & 9 \\
\hline Grand total & 20 & 11 & 12 & 16 & 25 & 19 & 8 & 18 & 15 & 144 \\
\hline
\end{tabular}

Table 3 shows the distribution of studies by industry and publication year. Two studies (Langlois and Robertson, 1992; Collinson and Wilson, 2006) covered two industries, hence are counted twice in the table. The studies are widely distributed across industries and over time, but this is far from a random sample. Software is most heavily represented with 39 studies. Almost half of the software studies (19) describe open-source projects: interest in this new organizational form grew between 2002 and 2009 and then dropped off, accounting for the rising and falling trend. 
Autos (19) and semiconductors (15) have the next highest number of studies followed by computers (12) and aircraft and defense (11). Information-based industries are overrepresented, while continuous process, extractive, and service industries are underrepresented in the sample.

\subsection{Analysis}

For the 103 studies in the initial sample, we examined and coded the studies' research designs and results to facilitate cross-comparisons. In particular, we noted whether the methodology employed was primarily quantitative (e.g., statistical correlation of design dependencies with organizational variables such as outsourcing/insourcing) or qualitative (e.g., interviews or surveys of perceived correlations between design dependencies and organizational variables). In this preliminary analysis, we divided our sample into subgroups according to the type of organization, but did not distinguish between descriptive and normative studies. We reported the results of our preliminary analysis in a 2010 working paper, and described some of the common features of the exceptions that contradicted the mirroring hypothesis. We then put the study aside until 2015.

In 2015 , on the encouragement of reviewers, we updated the sample and separated studies that were mainly descriptive from those that took a normative perspective. We also divided the studies of firms into (i) within-firm studies; (ii) studies of buyer-supplier relations; (iii) studies that looked at the management of knowledge; and (iv) studies of strategic alliances and consortia. By looking at these subgroups, we were able to classify the results in a more nuanced and theoretically consistent way.

\section{Overview of findings}

This section presents an overview of our findings.

\subsection{Descriptive studies}

As indicated, the descriptive studies in the sample, numbering 68, sought to establish correlations between technical and organizational variables. In the industry studies, the correlation studied was between a one-time change in product or process architecture and a corresponding change in industry structure. In the rest of the studies, the correlation studied was between measures of technical interdependency and measures of organizational linkages such as communication between developers or insourcing of components. Accordingly we classified the descriptive studies as exhibiting (i) high, (ii) partial, or (iii) no correlation between technical interdependency and organizational ties. Results for all groups involving firms are reported in Table 4. Results for open collaborative projects are reported in the first panel of Table 6 .

\subsection{Normative studies}

The normative studies, numbering 74 , sought to evaluate the performance outcomes associated with different ways of organizing work. The question in these studies was not, is mirroring prevalent, but instead, what are the performance consequences of setting up an organization to be mirrored or not. A study can support the normative form of the mirroring hypothesis by showing that the performance of mirrored organizations is good or the performance of unmirrored organizations is poor. Symmetrically, a study can fail to support the hypothesis by finding unmirrored organizations that performed well or mirrored organizations that performed poorly. Thus we adopted a six-part classification scheme for normative studies: (i) mirrored performed well, (ii) mirrored performed poorly, (iii) partially mirrored performed well, (iv) partially mirrored performed poorly, (v) unmirrored performed well, and (vi) unmirrored performed poorly.

Table 5 reports the results for the normative studies involving firms. The second panel of Table 6 reports the results for open collaborative projects.

\subsection{Summary of findings}

The descriptive studies of industries and firms showed that correlation between technical interdependencies and organizational ties is a common pattern both cross-sectionally and over time. Over two-thirds $(70 \%)$ of these studies provide strong evidence of mirroring; $22 \%$ provide partial support; while only $8 \%$ do not support the hypothesis. 
Table 4. Results for descriptive studies of firms

\begin{tabular}{|c|c|c|c|}
\hline Finding & \# & $\%$ & Categorization \\
\hline \multicolumn{4}{|l|}{ Industry studies } \\
\hline Mirrored & 7 & 100 & Dynamic mirroring \\
\hline \multicolumn{4}{|l|}{ Within firm } \\
\hline Mirrored & 12 & 75 & Technical dependencies correlated with communication linkages \\
\hline Partially mirrored & 3 & 19 & System integration correlated w/cross-module communication \\
\hline Unmirrored & 1 & 6 & $\begin{array}{l}\text { Technical interdependence uncorrelated w/communication } \\
\quad(\text { software }=1)\end{array}$ \\
\hline Total & 16 & 100 & \\
\hline \multicolumn{4}{|c|}{ Buyer-supplier relations } \\
\hline Mirrored & 13 & 76 & Modularity of components correlated w/outsourcing \\
\hline Partially mirrored & 1 & 6 & $\begin{array}{l}\text { Novel components exhibit high levels of communication between } \\
\text { buyer and supplier }\end{array}$ \\
\hline Unmirrored & 3 & 18 & $\begin{array}{l}\text { Technical interdependence uncorrelated w/communication } \\
\quad(\text { software }=2 \text { ) }\end{array}$ \\
\hline Total & 17 & 100 & \\
\hline \multicolumn{4}{|c|}{ Management of knowledge } \\
\hline Mirrored & 2 & 33 & $\begin{array}{l}\text { Patent citations mirror organization ties (1); Patent portfolios mirror } \\
\text { product architecture (1) }\end{array}$ \\
\hline Partially mirrored & 4 & 67 & $\begin{array}{l}\text { Concurrent sourcing (2); Patent portfolios do not mirror product } \\
\text { architecture (1); Ownership not correlated w/physical flows (1) }\end{array}$ \\
\hline Total & 6 & 100 & \\
\hline \multicolumn{4}{|l|}{ Alliances and consortia } \\
\hline Mirrored & 1 & 25 & Modularity correlated w/loosely coupled organizations \\
\hline Partially mirrored & 3 & 75 & $\begin{array}{l}\text { Interdependence weakly correlated w/communication (2); Modularity } \\
\text { weakly correlated w/loosely coupled organizations (1) }\end{array}$ \\
\hline Total & 4 & 100 & \\
\hline \multicolumn{4}{|c|}{ All groups involving firms } \\
\hline Mirrored & 35 & 70 & $\begin{array}{l}\text { Dynamic mirroring (7); Dependencies correlated w/communication } \\
\text { (12); Modularity correlated w/outsourcing (13); Other }(3)\end{array}$ \\
\hline Partially mirrored & 11 & 22 & $\begin{array}{l}\text { System integration correlated w/cross-module communication (3); } \\
\text { Various weak correlations (8) }\end{array}$ \\
\hline Unmirrored & 4 & 8 & $\begin{array}{l}\text { Technical interdependence uncorrelated w/communication }(4, \text { of } \\
\text { which } 3 \text { are in software) }\end{array}$ \\
\hline Total & 50 & 100 & \\
\hline
\end{tabular}

Support for the descriptive hypothesis is strongest in the industry studies, which generally showed that dynamic changes in technical architectures were followed by corresponding changes in industry structure. Support is also strong in the within-firm studies and in studies of buyer-supplier relations. Notably, however, in the latter two groups, about $25 \%$ of the studies showed partial or no mirroring, indicating that while mirroring is a common pattern, it is not universal.

Support for the descriptive hypothesis is markedly lower in studies of the management of knowledge and alliances and consortia. In these sub-groups, partial mirroring, in which firms explicitly invest in knowledge of technologies beyond their task boundaries, is the most commonly observed pattern.

The normative studies of firms offer a more nuanced view of mirroring as an organizational choice. Supporting the hypothesis, in 21 cases (of 64), mirroring was an explicit organizational goal and such organizations generally performed well. Further supporting the hypothesis, in 10 cases, unmirrored organizations performed poorly. The common thread linking the poor performers was premature modularization. These firms attempted to create modular organizations in response to new, supposedly modular technical architectures. However, they lacked knowledge of latent technical interdependencies; hence, their organizational ties turned out to be unmirrored with respect to the 
Table 5. Results for normative studies of firms

\begin{tabular}{|c|c|c|c|}
\hline Finding & $\# \mathbf{w}$ & $\%$ & Categorization \\
\hline \multicolumn{4}{|l|}{ Industry studies } \\
\hline Mirrored performed well & 2 & 67 & Dynamic mirroring strategy \\
\hline Mirrored performed poorly & 1 & 33 & Mirroring 'trap' \\
\hline Total & 3 & 100 & \\
\hline \multicolumn{4}{|l|}{ Within firm } \\
\hline Mirrored performed well & 8 & 44 & $\begin{array}{l}\text { Mirroring is an explicit design goal of system architect (4); Mirrored } \\
\text { systems perform well (4) }\end{array}$ \\
\hline Unmirrored performed poorly & 4 & 22 & Premature modularization \\
\hline Partially mirrored performed well & 2 & 11 & System integration requires cross-module coordination \\
\hline Unmirrored performed well & 4 & 22 & Dynamic contra-mirroring strategy \\
\hline Mirrored performed poorly & 2 & 11 & Mirroring 'trap' \\
\hline Total & 18 & 100 & \\
\hline \multicolumn{4}{|l|}{ Buyer-supplier relations } \\
\hline Mirrored performed well & 11 & 34 & Mirrored systems perform well (5); Dynamic mirroring (4); Other (2) \\
\hline Unmirrored performed poorly & 6 & 19 & Premature modularization \\
\hline Partially mirrored performed well & 12 & 38 & $\begin{array}{l}\text { System integration requires cross-module coordination (7); Relational } \\
\text { contracts perform well (2); Other (3) }\end{array}$ \\
\hline Unmirrored performed well & 3 & 9 & Relational contracts perform well \\
\hline Mirrored performed poorly & 3 & 9 & Mirroring 'trap' (2); Other (1) \\
\hline Total & 32 & 100 & \\
\hline \multicolumn{4}{|l|}{ Management of knowledge } \\
\hline Partially mirrored performed well & 4 & 100 & Firms w/broader knowledge perform well \\
\hline \multicolumn{4}{|l|}{ Total } \\
\hline \multicolumn{4}{|l|}{ Alliances and consortia } \\
\hline Partially mirrored performed well & 2 & 25 & Relational contracts perform well \\
\hline Unmirrored performed well & 6 & 75 & Relational contracts perform well \\
\hline Total & 8 & 100 & \\
\hline \multicolumn{4}{|l|}{ All groups involving firms } \\
\hline Mirrored performed well & 21 & 33 & $\begin{array}{l}\text { Mirrored systems perform well (9); Dynamic pro-mirroring strategy (6); } \\
\text { Mirroring explicit design goal (4); Other (2) }\end{array}$ \\
\hline Unmirrored performed poorly & 10 & 16 & Premature modularization \\
\hline Partially mirrored performed well & 20 & 31 & $\begin{array}{l}\text { System integration (9); Firms w/broader knowledge perform well (4); } \\
\text { Relational contracts perform well (4); Other (3) }\end{array}$ \\
\hline Unmirrored performed well & 13 & 20 & $\begin{array}{l}\text { Dynamic contra-mirroring strategy (4); Relational contracts perform well } \\
\text { (9) }\end{array}$ \\
\hline Mirrored performed poorly & 6 & 9 & Mirroring 'trap' (5); Other (1) \\
\hline Total & 64 & 100 & \\
\hline
\end{tabular}

true underlying technical architecture. The firms dealt with these unexpected interdependencies in an $a d$ hoc fashion, and their performance suffered as a result.

Partial mirroring, in which knowledge boundaries are drawn more broadly than operational boundaries, was observed in 20 of the normative studies. Notably, all firms that adopted this strategy performed well; hence, the finding "partially mirrored performed poorly" does not appear in Table 5. We believe this asymmetry is caused by the selection of research sites. Management scholars often seek to identify best practices (e.g., in systems integration) and thus select successful firms for study. Our sample indicates that many successful firms practice partial mirroring, but it does not tell us whether other firms have adopted this strategy and failed.

The normative studies also showed that it is possible for firms to strategically 'break the mirror' and perform well. One possibility is to implement modular partitions within their own boundaries. A second possibility is to build relational contracts that support high levels of technical interdependency across firm boundaries. Both types of 
Table 6. Results for open collaborative projects

\begin{tabular}{|c|c|c|c|}
\hline Finding & \# & $\%$ & Categorization \\
\hline \multicolumn{4}{|l|}{ Descriptive Studies } \\
\hline Mirrored & 5 & 28 & $\begin{array}{l}\text { Open-source codebases are modular w/low cognitive complexity (4); } \\
\text { Technical interdependence correlated w/communication (1) }\end{array}$ \\
\hline Partially mirrored & 3 & 17 & $\begin{array}{l}\text { Core-periphery organization structure (2); Most tasks performed by one } \\
\text { person, but two-person groups do not communicate (1) }\end{array}$ \\
\hline Unmirrored & 10 & 56 & $\begin{array}{l}\text { Transient groups work interdependently in brief spurts (5); Core develop- } \\
\text { ers contribute to many modules (4); Flawed study (1) }\end{array}$ \\
\hline Total & 18 & 100 & \\
\hline \multicolumn{4}{|l|}{ Normative studies } \\
\hline Mirrored performed well & 3 & 75 & Small teams with narrow responsibilities perform well (2); Other (1) \\
\hline Unmirrored performed poorly & 1 & 25 & Interdependent component w/multiple authors performs poorly \\
\hline Total & 4 & 100 & \\
\hline
\end{tabular}

strategic mirror-breaking can be a source of competitive advantage. We discuss within-firm modularizations in Section 5 and relational contracts in Section 6 below.

Last but not least, there is evidence of a mirroring 'trap' in the normative studies. In five cases, firms focused on the current technical architecture fell victim to architectural innovations originating outside their boundaries.

The evidence from open collaborative projects paints a very different picture from the studies involving firms. Here the majority of descriptive studies $(56 \%)$ did not support the mirroring hypothesis. The normative studies were generally supportive of mirroring but too few in number to be decisive. Below in Section 7, we will argue that these contradictory results arise because digital technologies make possible new modes of coordination that enable groups to deviate from classical mirroring as seen within firms.

The next three sections consider themes that cut across all analytical categories. Our intent is to bring together evidence from across the sample to reveal larger patterns. The themes we consider are as follows: (i) the dynamics of mirroring, (ii) collaboration across firm boundaries, and (iii) the new economics of digital tools and technologies.

\section{The dynamics of mirroring}

While we initially cast the descriptive and normative forms of the mirroring hypothesis as static propositions, there is ample theory and evidence that mirroring is in fact a dynamic process. Our initial formulations tested for the prevalence and performance of technical and organizational systems that were (or were not) mirrored at a specific point in time. However, in many cases, the researchers observed systems that were in flux, responding to new technological possibilities, new managerial strategies, or both. Viewing such cases longitudinally gives us insight into how mirroring relationships evolve over time.

Consider first the industry studies. In 9 of 10 cases, the industry was originally mirrored and its firms well adapted to the existing technical architecture. Then a new architecture was discovered with a better value proposition. The incumbents' organizational structures were misaligned relative to the new technology, and thus their organizations could not effectively respond to it. In the ensuing competition, firms either adapted their organizational structure (became mirrored) or exited.

In all seven descriptive industry studies, the new technical architecture was more modular than the dominant architecture at the time, and the industry subsequently broke apart. Typically, once the more modular architecture was in place and standards widely disseminated, specialized firms entered the industry by offering modules that competed with and eventually replaced the products of vertically integrated firms (Baldwin and Clark, 2000; Consoli, 2005; Galvin and Morkel, 2001; Jacobides, 2005; Langlois and Robertson, 1992; Lecocq and Demil, 2006; Sturgeon, 2002).

In two of the normative industry studies, industries evolved in the other direction, toward consolidation. In the case of bicycle drive trains, Shimano introduced a superior integrated product, the demand for modular products evaporated, and specialist firms exited the industry (Fixson and Park, 2008). In the British construction industry, 
unresolved technical interdependencies in the building process led specialist firms to merge, leading to significant industry consolidation (Cacciatori and Jacobides, 2005).

In contrast, in the third and final normative industry study, Sheffer and Levitt (2010) and Sheffer (2011) describe how the currently fragmented US construction industry (which mirrors current technology and building practice) is unable to implement system-level innovations that require coordination across firm boundaries. In this case, a mirrored industry structure is performing poorly in that it cannot access new opportunities involving technical architectures that do not mirror the current industry structure.

The evidence from the US construction industry thus suggests the existence of a mirroring 'trap'. This warning is echoed in four other studies. Henderson and Clark (1990) found that well-mirrored incumbents making photolithographic equipment lacked the internal capabilities to assimilate—or even perceive the advantages of - architectural innovations. Similarly, in the chemical, steel, and pharmaceutical industries, Collinson and Wilson (2006) and Dougherty and Dunne (2012) found that communication patterns and problem-solving strategies that had evolved under a prior technical architecture, prevented companies from perceiving innovations that cut across organizational boundaries. The consequences can be severe: Brusoni and Prencipe (2011) showed that reliance on the organizational ties developed under a previous technical architecture led to the grounding of two aircraft fleets due to design flaws.

The mirroring 'trap' is precisely the trap identified in the exploration-exploitation literature as a failure to explore (March, 1991; Benner and Tushman, 2003; Tushman and O'Reilly, 2004). Firms can avoid this trap via partial mirroring, in which they define their knowledge boundaries more broadly than their task boundaries. Although this strategy runs counter to strict information hiding, our sample indicates that it is both common and highly effective, as evidenced by 16 studies of buyer-supplier relations and the management of knowledge. Systems integrators who are responsible for the performance and evolution of an entire technical system are especially likely to adopt partial mirroring.

Partial mirroring is effective because, in complex systems with changing technologies, tasks and decisions are often more interdependent than system designers realize. Until a system is well-understood, latent dependencies will be present that can greatly compromise system performance and may cause a new system to fail. The 10 studies in our sample of poor performance due to premature modularization attest to this possibility. Partial mirroring strategies, by viewing the current technical architecture in a broader context, may identify these latent dependencies, and thus appropriately mirror the interdependencies that will affect the next generation of the product or process.

Significant architectural innovations are sometimes initiated by single firms in pursuit of competitive advantage. We have already discussed Shimano's introduction of an integrated bicycle drive train and its subsequent impact on the structure of that industry: in that case, Shimano's technology mirrored its own organization, but not that of its industry. In four other cases, tight-knit teams within single firms successfully created and capitalized on modular product architectures that did not mirror their own organizations (at least initially).

To understand the significance of these four cases, it is important to note that modular technical architectures do not arise naturally within firms. Communication linkages, collocation, and willingness to cooperate all work against the strict rules and information hiding that define truly modular systems. Thus, it is very common within firms for theoretical modules to collapse into one, large interconnected system.

Nevertheless, through an intense collaborative effort across multiple functional units, Black and Decker created an internal, modular product platform that allowed it to produce a wide range of power tools with standard components (Lehnerd, 1987). Sony designed the Walkman in the same way: as a reconfigurable platform that supported high variety and low cost (Sanderson and Uzumeri, 1995). Faced with the threat of holdup over a license, a team of software developers successfully modularized their platform to isolate the problematic code from the rest of the codebase (LaMantia et al., 2008). And when open-source developers rejected Mozilla's code because it was too complex, a team at Netscape redesigned the codebase so that it had the same functionality, but a higher degree of modularity (MacCormack et al., 2006).

In each of these cases, engineers and managers at the firms in question perceived the advantages of a modular architecture and made it a top priority for the team developing the design. They worked against their own organizational tendencies, and sought to change the existing technical architecture, thus contradicting Conway's prediction that "organizations ... are constrained to produce designs which are copies of the communication structures of these organizations."

However, not all such endeavors are successful. When firms attempt to create modular product and process architectures, nature sometimes stops the process by exposing unknown but critical interdependencies. The auto industry 
provides an example. During the 1990s and early 2000s, several automakers, including Ford, sought to move the design and testing of modules to their suppliers to gain the benefits of lower labor costs and more rapid innovation cycles (MacDuffie, 2013; Jacobides et al., 2015). However, as MacDuffie (2013) explains, "modularity as a property" cannot be instituted by corporate fiat: it relies on "modularization as a process" which involves identifying, researching, and resolving numerous technical interdependencies inherent in the technical structure of the vehicle. MacDuffie contrasts the modularization process at Ford, which was rapid but failed, with the process at Hyundai, which proceeded more slowly and appears to be succeeding. The dangers of premature or too-rapid modularization are borne out in nine other studies, four within firms and six involving buyers and suppliers.

High levels of complexity and high rates of technical change are characteristic of the most influential and dynamic sectors of modern economies. Our evidence on the dynamics of mirroring shows that, when systems are complex and technologies are changing rapidly, system knowledge is necessarily incomplete. Given incomplete knowledge, those guiding the evolution of these systems will not be able to perceive and account for all true underlying technical interdependencies in their explicit interface definitions. Understanding of the whole remains imperfect and incomplete even after much effort and many iterations. In such cases, organizational processes that deviate from strict mirroring are likely to be beneficial in terms of technical performance, competitive advantage, and the accumulation of valuable knowledge and capabilities. A "partial mirroring" strategy can be an effective way to explore and understand latent interdependencies that are not apparent under the current technical architecture. Furthermore, if the stakes are sufficiently high, firms may go further, overturning the current architecture for their own strategic advantage. Strategic mirror-breaking, if successful, can bring about wholesale changes to industry structure.

\section{Collaboration across firm boundaries}

The mirroring of technical dependencies with the boundaries of firms is the most common pattern in our sample of studies involving firms. However, there is also evidence that firms can sometimes manage dense technical interdependencies across their boundaries. A number of studies of buyer-supplier relations document early supplier involvement in the design of components, ongoing technical communication, and generally cooperative behavior on both sides of the relationship (Andersen, 1999; Bonaccorsi and Lipparini, 1994; Dibiaggio, 2007; Howard and Squire, 2007; Langner and Seidel, 2009; Miozzo and Grimshaw 2005; Sako, 2004). Supplier involvement and information sharing may vary across components in the same system: more complex and/or novel components generally are associated with higher levels of communication between buyers and suppliers (Monteverde and Teece, 1982; Novak and Eppinger, 2001; Takeishi, 2001, 2002; Cantamessa et al., 2006; Cabigiosu and Camuffo, 2012: Furlan et al., 2014). Another group of studies describes the workings of alliances and consortia, where multiple firms participate in the development of a tightly integrated, technically challenging new product or system (Appleyard et al., 2008; Argyres, 1999; Barlow, 2000; Miller et al., 1995; Scott, 2000; Snow et al., 2011; Staudenmayer et al., 2005; Tuertscher et al., 2014).

Much of the theory relevant to these exceptional cases has been developed since 2010. First is the idea of "epistemic interdependence" discussed in Section 2 (Puranam et al., 2012); second is the concept of "relational contracts" from economics and sociology; third is the idea of reciprocal learning leading to shared understanding. These concepts help to explain why and how independent firms can 'break the mirror' and work collaboratively on highly interdependent technical problems or systems.

Epistemic interdependence gives rise to the need for real-time coordination, which is facilitated by organizational ties (Puranam et al., 2012). Epistemic interdependence in turn is closely related to novelty. If a technical interdependence is well understood, it can be addressed via a rule or standard (Baldwin and Clark, 2000). But this process requires knowledge, and for this reason, novel technical systems and innovative components within existing systems will generate epistemic interdependence and thus call for higher-than-normal levels of communication and cooperation between the actors involved (Furlan et al., 2014).

Opportunities to create novel technical systems and/or innovative components often arise at the boundaries of firms. Indeed, all the cases of alliances and consortia in our sample involved the creation of new, technically challenging products or systems. Similarly, the cases involving higher-than-normal levels of buyer-supplier communication and cooperation generally involved novel or one-of-a-kind components. In other words, these firms were engaged in what Parmigiani and Rivera-Santos (2011) call "co-exploration" to develop new knowledge rather than "co-exploitation" of existing knowledge. Co-exploration involves "joint decision-making and rich ongoing 
communication between partners" which implicitly requires firms to 'break the mirror' by dissolving their organizational boundaries for the task at hand.

In such cases, why not unite the actors within the boundaries of a single firm? In fact, Garud and Munir (2008) document one such case. When designing the film and batteries for the novel SX-70 camera, Polaroid attempted to work with its suppliers, but they were unresponsive and eventually the company elected to design and produce these components in-house. However, in the cases of successful across-firm collaboration in our sample, the knowledge and capabilities needed to pursue the opportunity were distributed across several firms, and assembling them under one roof would have been costly and time-consuming. Thus, the firms chose not to integrate, but instead to build relational contracts.

There are two definitions of relational contract in the literature, one derived from economics, the other from law and sociology. The economic form, as discussed by Baker, Gibbons, and Murphy (2002) and Gibbons and Henderson (2012), assumes that agents are self-interested but able to calculate the present value of a continuing relationship. The "shadow of the future" thus restrains short-run opportunistic behavior. In contrast, the legal and sociological concept of a relational contract assumes that agents are social beings subject to "entangling strings of friendship, reputation, interdependence, morality and altruistic desires" (Macneil, 1987: 276). Though theoretically distinct, these concepts overlap in practice. They also require parties to the relationship to solve two basic problems: the problem of credibility (persuading counterparties one will act in good faith) and the problem of clarity (reaching a consistent, shared understanding of what is expected) (Gibbons and Henderson, 2012).

The problem of credibility can be addressed in three ways. First, the participants must have compatible motivations, that is, a superordinate goal that all know—and know the others know—can only be attained through joint, cooperative effort. Credibility can also be enhanced through repeated interaction. Each time one party fulfills a promise or goes beyond minimal performance, the others take note and adjust their assessments of reliability upward. Finally, the parties can make relationship-specific investments, creating resources that have little or no value except in the context of a continuing relationship.

All cases of successful across-firm collaboration in our sample were characterized by compatible motivation. In the alliances and consortia, the motivation generally took the form of a new, advanced technology or product, such as a next-generation manufacturing process, a military aircraft, or an advanced scientific instrument that would benefit all participants, but which none could build alone (Appleyard et al., 2008; Argyres 1999; Tuertscher et al., 2014). In buyer-supplier relations, the motivation was generally a better performing component and/or a more harmonious, responsive relationship (Bonaccorsi and Lipparini, 1994; Sako, 2004). Notably some suppliers proactively sought high levels of involvement as a means of strategic differentiation (Andersen, 1999; Miozzo and Grimshaw, 2005).

Consistent with the predictions of both economics and sociology, the across-firm collaborations in our sample were also generally long-lasting and involved both repeated interactions and relationship-specific investments. For example, the Japanese automakers Toyota, Honda, and Nissan induced their suppliers to share knowledge by investing in their suppliers' capabilities: they created teaching programs to replicate their in-house capabilities at suppliers' facilities, and they set clear rules for sharing the resulting financial gains cooperatively (Sako, 2004). In another case, Apple and SCI entered a contract committing the two firms to jointly assess the feasibility of each other's innovations. The contract's enforceable portion consisted of a 3-year commitment by Apple to purchase parts manufactured by SCI. However, the contract also contained unenforceable sections, which, the authors argue, were designed to build the firms' knowledge of each other's capacity for good faith collaboration and dispute resolution (Gilson, Sabel and Scott, 2009: 466).

The problem of clarity identified by Gibbons and Henderson (2012) is in fact part of a larger problem: how can diverse parties with few organizational ties work together effectively on a complex, technically interdependent product or system? To coordinate their actions in the face of underlying epistemic interdependency, participants must develop a shared understanding of the underlying technical system. In other words, contributors need to be able to "speak the same language" in terms of how they explain and interpret technical data and decisions. They also need to be able to anticipate when, where, and how to look for information from their counterparts.

In some cases in our sample, contributors lacked a shared understanding at the outset of the relationship, but subsequently invested time and effort to develop one. For example, Chrysler initially outsourced the development of windshield wipers for the Jeep Cherokee using a modular design approach with explicit interface specifications (Mikkola, 2003). Unfortunately, the supplier did not understand some of the specifications, the design failed, and the firms had to start over "from scratch" (p. 449). In the second (successful) design effort, Chrysler and the supplier increased the flow of technical information across their boundary: "Face-to-face meetings... daily phone calls, etc. 
became a habit" (p. 450). Sharing technical information in this way allowed the engineers at both firms to develop and maintain a common, accurate understanding of the evolving product design.

Across all cases of successful across-firm collaboration, we found that the mechanisms used by collaborating groups to share design information fell in two classes: (i) those that were analogues of traditional organizational ties; and (ii) those that constituted a genuine departure from tradition. The analogues to traditional organizational ties included broadband electronic (instead of face-to-face) communication, temporary physical collocation, and statusbased planning and dispute resolution. These devices created a set of direct, though informal, organizational ties between participants. In other cases, however, independent contributors did not develop as many direct ties, but coordinated their efforts implicitly, via shared product design and development tools. In these cases, transparency and direct involvement with the design served as a partial or complete substitute for direct ties between designers.

\section{The new economics of digital tools and technologies}

Digital technology has radically reduced both design and communication costs, which lie at the core of the economics of mirroring. In the 1990s, the ever-decreasing cost of computers and advent of the Internet gave rise to a variety of new organizational forms that were not firms. Among the most important was a new form of development organization based on open collaborative work, self-selection of tasks, and free sharing of intermediate and final designs (Boudreau and Lakhani, 2015). This community-based model of development is most evident in the arena of opensource software (Raymond, 2001), but it arises in sports and other communities as well (Franke and Shah, 2003; Baldwin et al., 2006). Quite often the development effort is spurred by users or people close to users (e.g., the parents of sick children) who have a strong interest in advancing a technology that for-profit firms are not pursuing.

Significantly, of the three organizational groups in our sample, open collaborative projects, most of which focused on software, provided the least support for the mirroring hypothesis. ${ }^{6}$ In this section, we look more closely at studies of open collaborative projects to see what effect digital technologies have had on mirroring. Three patterns are noteworthy: (i) the use of digital technology to assemble transient groups of problem-solvers to work interdependently for limited periods of time; (ii) technical systems with high modularity and low cognitive complexity but no information hiding; and (iii) core-periphery technical and organizational structures, which might or might not be mirrored. We discuss each of these patterns below.

First, digital technologies make it possible to assemble groups of problem solvers to work intensively on relatively small problems for limited spans of time. If the participants work independently, disclosing only their final solutions, then their technical dependencies and organizational ties will be mirrored. But in open collaborative projects it is more common for participants to see and build on each other's work. Thus in the GNU Project of the Free Software Foundation, Elliott and Scacchi (2003) found that geographically distributed contributors collaborated directlyoften in real time-using mailing lists and instant messaging. Similarly, in the FreeBSD project, Spinellis (2006) found that developers from different parts of the world contributed to the same module on the same day.

Indeed, contributors do not need to cooperate to work interdependently: in some software contests competitors can see each other's code, adopt it, and modify it with no explicit constraints ${ }^{7}$ (Gulley, 2001, 2004; Lakhani et al., 2013; Boudreau and Lakhani, 2015). Observing a number of such contests, Gulley (2004) found that contestants made rapid, iterative changes to each other's work so that the winning entry manifested the "tangled effort of dozens of people" (p. 23). These dynamics have also been observed in sports competitions and open innovation contests (Baldwin et al., 2006; Kokshagina et al., 2015).

For this mode of collaboration to be feasible, participants must have not only broadband, all-to-all communication, but also tools that support rapid generate-test cycles (Simon, 1981). The emerging artifact must be easily understood (transparent) and subject to manipulation (actionable) (Zuboff, 1988; West and O'Mahony, 2008). Many digital artifacts have the property of actionable transparency. Physical artifacts are harder to act upon, although simulation models and technologies like 3-D printing shorten generate-test cycles and make them actionable to a degree.

The members of the ad hoc groups that form in open-source projects or participate in contests are mirrored in the sense of having dense communication linkages while they are working. Also, although they are not members of the

6 In the within- and across-firm studies, most software organizations were mirrored, but three were not (Grunwald and Kieser, 2007; Herbsleb et al. 2005; Srikanth and Puranam, 2011).

7 In effect, these regimes provide contestants with no property rights in their designs. 
same firm, they work within frameworks-open-source communities or sponsored contests-that keep opportunism within the bounds of community norms and fair play. Hence, this pattern does not contradict the mirroring hypothesis so much as show that with digital technology, temporary organizational ties can quickly be created at low cost to support highly interdependent collaboration.

The second pattern we observed was the conundrum of high modularity and low cognitive complexity without information hiding. To attract the efforts of part-time and volunteer contributors, open collaborative projects cannot be too complex. Information hiding is the traditional way to reduce cognitive complexity: the problem is broken down into parsimoniously linked sub-problems; technical interdependencies are partitioned in modules; and each module becomes the responsibility of an interactive team of individuals (Simon, 1962; Parnas, 1972, 1978; Baldwin and Clark, 2000).

In fact, four studies in our sample found that open-source projects had lower cognitive complexity and were more modular than proprietary projects (Herraiz et al., 2006; MacCormack et al., 2006, 2008; Baldwin et al., 2014). However, three other studies found no evidence of strict partitioning within codebases nor any correspondence between identifiable organizational groups and specific modules (Bird et al., 2008; Bowman and Holt, 1998; Gutwin et al., 2004). These studies contradict the idea that modularity and low cognitive complexity must be achieved through rule-based partitions and information hiding (Parnas, 1972, 1978).

This conundrum can be partially explained by the phenomenon of "hidden structure" in software codebases. Looking at a large sample of codebases developed in both open-source communities and in firms, Baldwin et al. (2014) found that most did not contain many separate modules but instead had a "core-periphery" structure, with one central module, or "core." Open-source codebases were more modular in the sense of having consistently smaller cores than comparable proprietary codebases. A small core in turn means that changes in one part of the system will not propagate as readily to other parts, and thus contributes to low cognitive complexity. Thus it is possible to have high modularity (low propagation) and low cognitive complexity without strict information hiding.

When the individual components of a technical system can be comprehended easily and changed readily without propagating into the larger system, developers may not need to communicate directly with one another. Instead, the system itself summarizes its own state and interaction with the changing system suffices to coordinate the work of many independent agents. This method of coordination is known as "stigmergy": it is characteristic of social insects, neuronal networks, chess games, data repositories, and distributed computing (Heylighen, 2006; Bolici et al., 2009).

Stigmergic coordination is possible only if each task is epistemically independent of other tasks so that each actor can choose his or her best course of action without exchanging information with other actors. The studies in our sample provide evidence of stigmergic coordination especially with respect to small contributions: people inspect the state of the system, change it, submit their changes, and see what happens. Sophisticated tools make it possible to "track back" to previous system states if the changes turn out to be damaging.

However, even highly modular systems have some parts that are more complex and technically interdependent than others. Thus a third pattern we observed was the formation of a "core-periphery" organizational structure (Koch and Schneider, 2002; von Krogh et al., 2003; Mockus et al., 2000; 2002). In a core-periphery organization, the majority of participants contribute to smaller, localized components in the codebase, while a small group of "core contributors" is responsible for the larger components and the system as a whole. The core contributors generally range throughout the system and frequently communicate with one another to coordinate their activities and arrive at a common vision.

To date there have been no studies attempting to correlate the core-periphery technical architecture of a codebase with a core-periphery organizational structure in the community. In a given project, both might exist, but the organizational structure might not be mapped onto the technical structure as the mirroring hypothesis requires. Nevertheless it is reasonable to hypothesize that core members of a project might be drawn into the technical core of the system. The technical core, by definition, is dense with technical interdependencies; hence, complex problems requiring communication and coordination are likely to arise in its vicinity. As a result, core members of the community pursuing their normal problem-solving and systems integration activities may frequently find themselves working in the technical core even if they do not know exactly where it is.

\section{Conclusion}

In this article we have attempted to present a comprehensive view of the mirroring hypothesis. The hypothesis predicts that there will (or should) be a correspondence between the dependencies in the technical architecture of a complex system and organizational ties among those responsible for designing or sustaining it. In mirrored organizations, 
organizational ties that facilitate communication and joint problem-solving are dense where technical problems are most likely to arise. We began by formally defining the hypothesis in terms of a correspondence between two network graphs. We developed descriptive and normative versions of the hypothesis and then reviewed the empirical evidence in industry studies, within and across firms, and in open collaborative projects.

\subsection{Overview of results}

Studies of industry dynamics showed that, through the economics of mirroring, a radical change in technical architecture can over time reshape the structure of an entire industry. Furthermore, the change in technical architecture might be instigated as a strategic move by a single firm. In other cases, however, most notably the auto industry, attempts by firms to reshape the industry failed because the firms had not accounted for latent technical interdependencies well enough to support the desired shift in firm boundaries and capabilities.

Studies of the dynamics of mirroring also showed that, when the technologies are changing and becoming more complex, dimensions of technical performance are likely to be more interdependent than system designers realize. Knowledge about such systems is always incomplete and evolving, and thus firms should purposefully invest in organizational arrangements, practices, and routines that serve to expand their knowledge boundaries beyond their task boundaries. Such "partially mirrored" systems are costlier to sustain than strictly mirrored systems, but they allow firms to avoid premature modularization, respond to architectural innovations arising outside their boundaries, and in some cases initiate architectural innovations to gain competitive advantage.

Studies of buyer-supplier relations and alliances and consortia also showed that it is possible to achieve high levels of technical integration and cooperation across firm boundaries via relational contracts. Such contracts require there to be significant incremental value in a continuing relationship. They become more robust through repeated positive interactions, relationship-specific investments, and shared understanding of the evolving technical system. Significantly, their use was generally motivated by the high costs and capabilities requirements associated with developing exceptionally complex technology. Thus the prevalence of collaboration across firm boundaries is likely to rise as more firms move in this general technological direction.

Finally, new digital technologies have made possible new methods of coordination. Specifically, it is now possible to assemble groups of problem-solvers from around the globe to work interdependently on a common problem for short periods of time. It is also possible for dispersed agents to work asynchronously and without direct communication, coordinating their work stigmergically by interacting with a changing artifact. Lastly, many digital systems have evolved to a dual core-periphery structure in which the technical architecture has a single complex core and peripheral components, while the organization has a core of consistently engaged contributors and a periphery of transient participants. No study has yet looked to see whether the technical and organizational cores in these systems are mirrored: this is an opportunity for future work.

\subsection{Boundary conditions on mirroring}

On the whole, the mirroring hypothesis captures quite well the central relationship between technical dependencies and organizational ties in complex technical systems both within and across firms. However, when the underlying technologies are rapidly changing and becoming more complex, breaking away from the logic of strict mirroring can lead to better technical performance and competitive advantage. Figure 3 summarizes our view of the boundary conditions applicable to the mirroring hypothesis based on our empirical data. The vertical axis indicates the rate of technical change and growing complexity: as explained above, these features tend to go hand-in-hand. The horizontal axis indicates the composition of the system: does it contain physical components, digital components, or both. (Today as digital technologies diffuse through the economy, the number of digital and mixed systems is growing, and the number of purely physical systems is shrinking.)

In physical and mixed systems, when technologies are relatively stable and complexity is growing slowly, mirroring is a common and generally efficient way to deploy organizational resources to solve technical problems. As the rate of technical change increases and systems become more complex, however, firms taking on the role of systems integrators must have system-wide knowledge extending beyond the tasks they perform in-house. At the same time, architectural innovations outside the boundaries of a given firm become more likely and strict mirroring can become a trap. Partial mirroring is then the recommended strategy. 


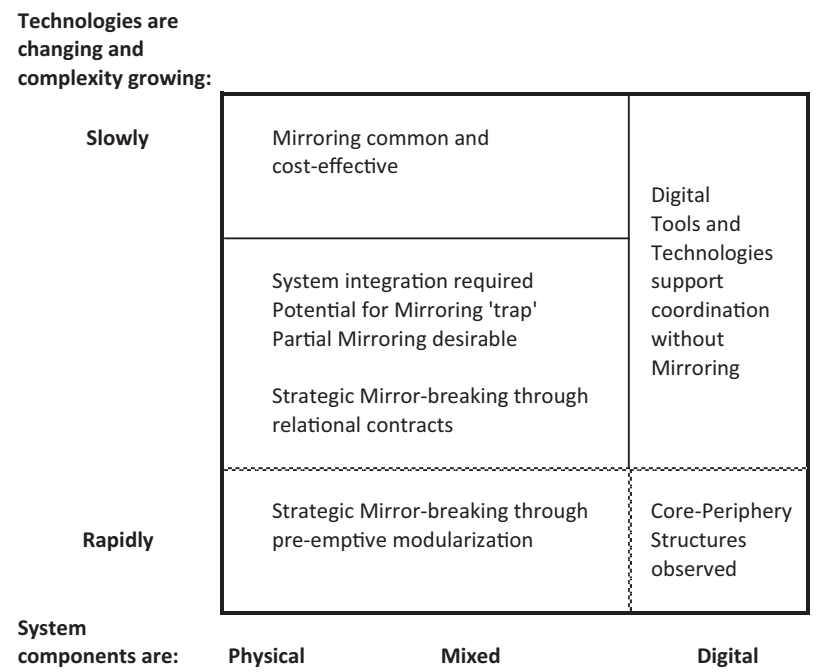

Figure 3. Boundary conditions on the mirroring hypothesis.

Responding to higher rates of technical change and growing complexity of systems, firms may also choose as a matter of strategy to 'break the mirror' by investing in relational contracts. In these cases, firms bilaterally or multilaterally seek to foster high levels of communication and cooperation across their boundaries with selected partners. These firms strategically 'break the mirror' by increasing technical interdependencies across their boundaries, but do so in the context of a long-term, mutually advantageous relationship.

A less common form of mirror-breaking (in our sample) is for a single firm to create a new, modular technical architecture within its own boundaries. The advantages of modular architectures generally are higher levels of flexibility and adaptability, made possible by lower levels of complexity achieved through information hiding. These advantages enable a firm to drive the rate of technical change in its products and systems to even higher levels (Baldwin and Clark, 2000). Thus firms electing to modularize within their own boundaries are often in highly dynamic technical environments. They may be seeking to pre-empt rivals by increasing the rate of technical change necessary to compete in their product markets.

Digital technologies are shown in the right-hand column. Our sample of open collaborative projects shows that digital tools and technologies can support coordination in ways that go beyond the organizational ties of traditional mirroring. Stigmergic coordination can replace direct communication. High bandwidth communication makes collocation unnecessary. Self-selection and voluntary participation in contests and communities can take the place of formal employment relations. While these new coordination methods were most striking in studies of open collaborative projects, they are no less available to firms today. As digital technologies spread into mixed systems, we expect these methods to diffuse as well.

We also observed core-periphery technical and organizational systems in open collaborative projects, but not in firms. However, core-periphery is the characteristic structure of a platform, which is an increasingly common architecture for systems made up of hardware and software. The core-periphery structure has advantages in that it takes account of different degrees of modularity, interdependence, and cognitive complexity in different parts of a large system and deals with these using different organizational methods. Thus as software becomes more embedded in physical systems, we expect core-periphery structures and corresponding methods of coordination to become widespread.

\subsection{Limitations}

This study is limited by sample and methodology. In terms of the sample, we cast a wide net by surveying numerous publication outlets, and adding works known to us or brought to our attention. However, it is impossible to construct a truly comprehensive sample. The second limitation lies in the fact that our methods of classification were necessarily subjective and more coarse-grained than the studies themselves. We are only able to describe the most common patterns, not all patterns. A third limitation is that, in the normative studies, successes outnumber failures 
by a margin of three to one (48 successes to 16 failures). This asymmetry is likely due to scholars' legitimate interest in best practices as found in successful firms. However, it leaves some gaps in the data: for example, we have no cases in which a strategy of partial mirroring was unsuccessful.

\subsection{Future work}

This study opens up several lines of future research. First, we have seen that when technical systems are changing rapidly and becoming more complex, deviations from the logic of strict mirroring will be beneficial for both firms and groups of firms (ecosystems). In particular, it is advantageous for these firms to draw their knowledge boundaries more broadly than their task boundaries and to consider whether to 'break the mirror' through relational contracts or pre-emptive modularization. How then does a division of labor involving overlapping knowledge shape the evolution of capabilities (Jacobides, 2006; Argyres and Zenger, 2012)? There is evidence in our sample that integrated firms can both initiate and respond to architectural innovations more effectively than specialized firms (Fixson and Park, 2008; Kapoor and Adner, 2012). But such firms can also be blind-sided by new modular architectures or may pursue modularity inappropriately (Baldwin and Clark, 2000; MacDuffie, 2013; Jacobides et al., 2015). From a normative standpoint, how can such firms know when it is advantageous to break the mirror, and when it is foolhardy? Relatedly, what are the limits of modularization as a process: are some end products just too intrinsically interdependent to break apart into modules?

Second, core-periphery technical and organizational structures are becoming more prevalent as many firms are attempting to turn their products into platforms that can attract external complementors. Scholars are beginning to study the organizational changes firms must make to support such strategies, but this work has only just begun (Gawer and Phillips, 2013; Lifshitz-Assaf, 2014; Altman et al., 2014). The relationship between technical dependencies and organizational ties in platforms has not yet been addressed and is a promising area for future work. Relatedly, in platforms, how should firms trade-off the flexibility of modular architectures vs. the stability of relational contracts?

Finally, in open collaborative projects, a relatively new organizational form, we have seen that digital technology can support both transient organizational structures and stigmergic coordination. Firms are increasingly adopting these practices both internally and externally. The question then arises: in a digitally connected world, what constitutes an effective organizational tie and what ties are needed to resolve technical dependencies and get work done?

We began this article by noting that innovation is a process of defining problems and developing knowledge needed to solve them effectively. The mirroring of technical interdependencies and organizational ties is a solution to the problem of managing complex technical systems while conserving scarce cognitive resources. Mirroring has benefits, thus not surprisingly, it is a prevalent pattern in the economy at large. But it also has costs, especially when the underlying technology is dynamic and complex and architectural innovation a likely possibility. Digital tools and technologies also give rise to new patterns including transient mirroring, stigmergic coordination, and core-periphery structures. As digital technology diffuses, we expect these new patterns to become more common. Our study thus captures mirroring at a time of transition: from the stable architectures and closed organizations of the past to increasingly dynamic architectures and open, evolving organizational ecosystems in the future.

\section{Acknowledgements}

An earlier version of this article appeared as a chapter in the first author's doctoral dissertation, "Three essays on the structure of technical collaboration." The authors extend sincere thanks to the dissertation committee, Margo Seltzer and Karim Lakhani, for their support. They also thank Sebastian Fixson, James Herbsleb, James Howison, Peter Murmann, Phanish Puranam, Mary Tripsas, Michael Tushman, and Eric von Hippel for detailed comments on previous drafts. Finally, the authors would like to specially thank the Associate Editor, Michael Jacobides, and Reviewers Arnaldo Camuffo and John Paul MacDuffie who provided comments and suggestions that greatly improved both the substance and the structure of the paper. The financial support of the HBS Division of Research and Doctoral Programs is gratefully acknowledged. The authors alone are responsible for any remaining errors or omissions.

\section{References (Not in Sample)}

Alchian, A. A. and H. Demsetz (1972), 'Production, information costs, and economic organization,' American Economic Review, 62, $777-795$. 
Alexander, C. (1964), Notes on the Synthesis of Form. Harvard University Press: Cambridge, MA.

Allen, T. J. (1984), Managing the Flow of Technology: Technology Transfer and the Dissemination of Technological Information Within the R\&D Organization. MIT Press: Cambridge, MA.

Altman, E. J., F. Nagle and M. Tushman (2014), 'Innovating without information constraints: organizations, communities, and innovation when information costs approach zero,' Harvard Business School Organizational Behavior Unit Working Paper, No. 14043, Available at SSRN: http://dx.doi.org/10.2139/ssrn.2362855

Argyres, N. S. and T. R. Zenger (2012), 'Capabilities, transaction costs, and firm boundaries,' Organization Science, 23(6), 1643-1657.

Arthur, W. B. (2009), The Nature of Technology: What it is and How it Evolves. Simon and Schuster: New York.

Baker, G., R. Gibbons and K. J. Murphy (2002), 'Relational contracts and the theory of the firm,' Quarterly Journal of Economics, $117(1), 39-84$.

Baldwin, C. Y. (2015), 'Bottlenecks, modules and dynamic architectural capabilities,' Harvard Business School Finance Working Paper, No. 15-028, Available at SSRN: http://dx.doi.org/10.2139/ssrn.2512209

Baldwin, C. Y. (2008), 'Where do transactions come from? Modularity, transactions, and the boundaries of firms,' Industrial and Corporate Change, 17(1), 155-195.

Benner, M. J. and M. L. Tushman (2003), 'Exploitation, exploration, and process management: the productivity dilemma revisited,' Academy of Management Review, 28(2), 238-256.

Boudreau, K. J. and K. R. Lakhani (2015), “'Open” disclosure of innovations, incentives and follow-on reuse: theory on processes of cumulative innovation and a field experiment in computational biology,' Research Policy, 44(1), 4-19.

Brusoni, S. and A. Prencipe (2001), 'Unpacking the black box of modularity: technologies, products and organizations,' Industrial and Corporate Change, 10(1), 179-205.

Bucciarelli, L. L. (1994), Designing Engineers. MIT Press: Cambridge, MA.

Chandler, A. D. (1977), The Visible Hand: The Managerial Revolution in American Business. Harvard University Press: Cambridge, MA.

Chesbrough, H. W. and D. J. Teece (1996), 'When is virtual virtuous,' Harvard Business Review, 74(1), 65-73.

Conway, M. (1968), 'How do committees invent?' Datamation, 14(4), 28-31.

Drazin, R. and A. H. Van de Ven (1985), 'Alternative forms of fit in contingency theory,' Administrative Sciences Quarterly, 30(4), 514-539.

Eppinger, S. D. (1991), 'Model-based approaches to managing concurrent engineering,' Journal of Engineering Design, 2(4), 283-290.

Franke, N. and S. Shah (2003), 'How communities support innovative activities: an exploration of assistance and sharing among endusers,' Research Policy, 32, 157-178.

Galbraith, J. (1974), 'Organization design: an information processing view,' Interfaces, 4(3), 28-36.

Gawer, A. and N. Phillips (2013), 'Institutional work as logics shift: the case of Intel's transformation to platform leader,' Organization Studies, 34(8), 1035-1071.

Gibbons, R. and R. Henderson (2012), 'Relational contracts and organizational capabilities,' Organization Science, 23(5), 1350-1364.

Gilson, R. J., C. F. Sabel and R. E. Scott (2009), 'Contracting for innovation: vertical disintegration and interfirm collaboration,' Columbia Law Review, 431-502.

Helfat, C. E. and M. Campo-Rembado (2010), 'Integrative capabilities, vertical integration, and innovation over successive technology lifecycles,' Working Paper, Tuck School of Business at Dartmouth.

Heylighen, F. (2006), Why is Open Access Development so Successful? Stigmergic organization and the economics of information. arXiv, preprint cs/0612071. Available at http://arxiv.org/ftp/cs/papers/0612/0612071.pdf, accessed 12 September 2015.

Jacobides, M. G. (2006), 'The architecture and design of organizational capabilities,' Industrial and Corporate Change, 15(1), 151-171.

Jacobides, M. G. and S. G. Winter (2012), 'Capabilities: structure, agency, and evolution,' Organization Science, 23(5), $1365-1381$.

Jacobides, M. G., T. Knudsen and M. Augier (2006), 'Benefiting from innovation: value creation, value appropriation and the role of industry architectures,' Research Policy, 35, 1200-1221.

Kleinbaum, A. M., T. Stuart and M. Tushman (2008), 'Communication (and Coordination?) in a Modern, Complex Organization,' Harvard Business School Entrepreneurial Management Working Paper 09-004. Available at SSRN: http://ssrn.com/abstract= 1162171

Lakhani, K. R., K. J. Boudreau, P. R. Loh, L. Backstrom, C. Baldwin, E. Lonstein, M. Lydon, A. MacCormack, R. A. Arnaout and E. C. Guinan (2013), 'Prize-based contests can provide solutions to computational biology problems,' Nature Biotechnology, 31(2), 108-111.

Langlois, R. N. (2002), 'Modularity in technology and organization,' Journal of Economic Behavior and Organization, 49(1), 19-37. 
Lawrence, P. R. and J. W. Lorsch (1967), 'Differentiation and integration in complex organizations,' Administrative Science Quarterly, 12(1), 1-47.

Lifshitz-Assaf, H. (2014), From problem solvers to solution seekers: dismantling Knowledge Boundaries at NASA. Available at SSRN 2431717.

Macneil, I. R. (1987), 'Relational contract theory as sociology: a reply to Professors Lindenberg and de Vos,' Journal of Institutional and Theoretical Economics (JITE)/Zeitschrift für die gesamte Staatswissenschaft, 143(2), 272-290.

March, J. G. (1991), 'Exploration and exploitation in organizational learning,' Organization Science, 2(1), $71-87$.

Milgrom, P. and J. Roberts (1990), 'The economics of modern manufacturing: technology, strategy, and organization,' American Economic Review, 80(3), 511-528.

Nelson, R. R. and S. G. Winter (1982), An Evolutionary Theory of Economic Change. Harvard University Press: Cambridge, MA.

Nickerson, J. A. and T. R. Zenger (2004), 'A knowledge-based theory of the firm-the problem-solving perspective,' Organization Science, 15(6), 617-632.

Nonaka, I. (1994), 'A dynamic theory of organizational knowledge creation,' Organization Science, 5(1), 14-37.

Parmigiani, A. and M. Rivera-Santos (2011), 'Clearing a path through the forest: a meta-review of interorganizational relationships,' Journal of Management, 37(4), 1108-1136.

Parnas, D. L. (1972), 'On the criteria to be used in decomposing systems into modules,' Communications of the ACM, 15(12), 1053-1058.

Parnas, D. L. (1978), 'Some software engineering principles,' in D. Hoffman and D. Weiss (eds), Software Fundamentals: Collected Papers by David L. Parnas. Addison-Wesley: Boston, MA.

Pisano, G. P. and D. J. Teece (2007), 'How to capture value from innovation: shaping intellectual property and industry architecture,' California Management Review, 50(1), 278-296.

Puranam, P., O. Alexy and M. Reitzig (2014), 'What's “new” about new forms of organizing?' Academy of Management Review, 39(2), 162-180.

Puranam, P., M. Raveendran and T. Knudsen (2012), 'Organization design: the epistemic interdependence perspective,' Academy of Management Review, 37(3), 419-440.

Raymond, E. S. (2001), The Cathedral \& the Bazaar Musings on Linux and Open Source by an Accidental Revolutionary. O'Reilly Media, Inc.

Sanchez, R. and J. T. Mahoney (1996), 'Modularity, flexibility, and knowledge management in product and organization design,' Strategic Management Journal, 17(S2), 63-76.

Simon, H. (1957), Models of Man, Social and Rational: Mathematical Essays on Rational Human Behavior in a Social Setting. Wiley: New York.

Simon, H. A. (1962), 'The architecture of complexity,' Proceedings of the American Philosophical Society, 106(6), 467-482.

Simon, H. A. (1981), The Sciences of the Artificial, 2nd edn. MIT Press: Cambridge, MA.

Steward, D. V. (1981), 'The design structure system: a method for managing the design of complex systems,' IEEE Transactions on Engineering Management, (3), 71-74.

Teece, D. J., G. Pisano and A. Shuen (1997), 'Dynamic capabilities and strategic management,' Strategic Management Journal, 18(7), 509-533.

Thompson, J. D. (1967), Organizations in Action: Social Science Bases of Administrative Theory. McGraw-Hill: New York.

Tushman, M. L. (1979), 'Work characteristics and subunit communication structure: a contingency analysis,' Administrative Science Quarterly, 24, 82-98.

Tushman, M. L. and D. A. Nadler (1978), 'Information processing as an integrating concept in organizational design,' Academy of Management Review, 3(3), 613-624.

Tushman, M. L. and C. A. O’Reilly III (2004), 'The ambidextrous organization: managing evolutionary and revolutionary change,' in M. L. Tushman and P. Anderson (eds), Managing Strategic Innovation and Change, 2nd edn. Oxford University Press, New York.

Ülkü, S. and G. M. Schmidt (2011), 'Matching product architecture and supply chain configuration,' Production and Operations Management, 20(1), 16-31.

Ulrich, K. (1995), 'The role of product architecture in the manufacturing firm,' Research Policy, 24(3), 419-440.

von Hippel, E. (1990), 'Task partitioning: an innovation process variable,' Research Policy, 19(5), 407-418.

Weick, K. E. (1976), 'Educational organizations as loosely coupled systems,' Administrative Science Quarterly, 21(1), 1-19.

West, J. and S. O'Mahony (2008), 'The role of participation architecture in growing sponsored open source communities,' Industry and Innovation, 15(2), 145-168.

Whitney, D., E. Crawley, O. de Weck, S. Eppinger, C. Magee, J. Moses, W. Seering, J. Schindall and D. Wallace (2004), 'The Influence of Architecture in Engineering Systems,'in Engineering Systems Monograph. MIT: Cambridge, MA, http://mit.sustech. edu/NR/rdonlyres/0708296E-EAFB-4FA9-9710-56E7B20AB34A/0/arch_esd.pdf (accessed 12 September 2015).

Williamson, O. E. (1975), Markets and Hierarchies. Free Press: New York. 
Williamson, O. E. (1985), The Economic Intstitutions of Capitalism. Simon and Schuster: New York.

Williamson, O. E. (1991), 'Comparative economic organization: the analysis of discrete structural alternatives,' Administrative Science Quarterly, 36(2), 269-296.

Wolter, C. and F. M. Veloso (2008), 'The effects of innovation on vertical structure: perspectives on transaction costs and competences,' Academy of Management Review, 33(3), 586-605.

Zuboff, S. (1988), In the Age of the Smart Machine: the Future of Work and Power. Basic Books: New York.

\section{References (in Sample) Descriptive Studies}

Almeida, P., J. Song and R. M. Grant (2002), 'Are firms superior to alliances and markets? An empirical test of cross-border knowledge building,' Organization Science, 13(2), 147-161.

Argyres, N. and L. Bigelow (2010), 'Innovation, modularity, and vertical deintegration: evidence from the early US auto industry,' Organization Science, 21(4), 842-853.

Bigelow, L. S. and N. Argyres (2008), 'Transaction costs, industry experience and make-or-buy decisions in the population of early US auto firms,' Journal of Economic Behavior and Organization, 66(3), 791-807.

Atalay, E., A. Hortaçsu and C. Syverson (2014), 'Vertical integration and input flows,' The American Economic Review, 104(4), 1120-1148. Baldwin, C. Y. and K. B. Clark (2000), Design rules: The Power of Modularity, Vol. 1, Chapters 1 and 14. MIT Press: Cambridge, MA. (Chapter 7 is also counted as normative within firm.)

Baldwin, C., C. Hienerth and E. von Hippel (2006), 'How user innovations become commercial products: a theoretical investigation and case study,' Research Policy, 35(9), 1291-1313.

Baldwin, C., A. MacCormack and J. Rusnak (2014), 'Hidden structure: using network methods to map system architecture,' Research Policy, 43(8), 1381-1397.

Barrett, M., E. Oborn, W. J. Orlikowski and J. Yates (2012), 'Reconfiguring boundary relations: robotic innovations in pharmacy work,' Organization Science, 23(5), 1448-1466.

Bird, C., D. Pattison, R. D'Souza, V. Filkov and P. Devanbu (2008), 'Latent social structure in open source projects,' in Proceedings of the 16th ACM SIGSOFT International Symposium on Foundations of Software Engineering. ACM, 24-35.

Blair, M. M., E. O. H. O'Connor and G. Kirchhoefer (2011), 'Outsourcing, modularity, and the theory of the firm,' Brigham Young University Law Review, 2011(2), 263-314.

Bowman, I. T. and R. C. Holt (1998), 'Software architecture recovery using Conway's law,' in Proceedings of the 1998 Conference of the Centre for Advanced Studies on Collaborative Research. Available from http://citeseerx.ist.psu.edu/viewdoc/download?doi=10. 1.1.10.1155\&rep=rep1\&type=pdf.

Cantamessa, M., M. Milanesio and E. Operti (2006), 'Value chain structure and correlation between design structure matrices,' in Advances in Design. Springer: London, 303-313.

de Souza, C. R. B., D. Redmiles, L. -T. Cheng, D. Millen and J. Patterson (2004), 'How a good software practice thwarts collaboration: the multiple roles of APIs in software development,' in Proceedings of 2004 ACM SIGSOFT International Symposium on Foundations of Software Engrgy. Newport Beach: CA.

Consoli, D. (2005), 'The dynamics of technological change in UK retail banking services: an evolutionary perspective,' Research Policy, 34(4), 461-480.

De Santana, A. M., F. Q. Da Silva, R. C. De Miranda, A. Mascaro, T. B. Gouveia, C. V. Monteiro and A. L. Santos (2013), 'Relationships between communication structure and software architecture: an empirical investigation of the Conway's law at the Federal University of Pernambuco,' in 2013 3rd International Workshop on Replication in Empirical Software Engineering Research (RESER). IEEE, 34-42.

De Souza, C. R., D. Redmiles, L. T. Cheng, D. Millen and J. Patterson (2004), 'How a good software practice thwarts collaboration: the multiple roles of APIs in software development,' ACM SIGSOFT Software Engineering Notes, 29(6), 221-230.

Elliott, M. S. and W. Scacchi (2003), 'Free software development: cooperation and conflict in a virtual organizational culture,' in Free/Open Source Software Development. Available at https://www.researchgate.net/publication/200026298_Free_Software_ Development_Cooperation_and_Conflict_in_a_Virtual_Organizational_Culture.

Furlan, A., A. Cabigiosu and A. Camuffo (2014), 'When the mirror gets misted up: modularity and technological change,' Strategic Management Journal, 35(6), 789-807.

Cabigiosu, A. and A. Camuffo (2012), 'Beyond the "mirroring" hypothesis: product modularity and interorganizational relations in the air conditioning industry,' Organization Science, 23(3), 686-703.

Galvin, P. and A. Morkel (2001), 'The effect of product modularity on industry structure: the case of the world bicycle industry,' Industry and Innovation, 8(1), 31-47.

Grimaldi, R. and S. Torrisi (2001), 'Codified-tacit and general-specific knowledge in the division of labour among firms: a study of the software industry,' Research Policy, 30(9), 1425-1442. 
Grunwald, R. and A. Kieser (2007), 'Learning to reduce interorganizational learning: an analysis of architectural product innovation in strategic alliances,' Journal of Product Innovation Management, 24(4), 369-391.

Gulati, R. and P. Puranam (2009), 'Renewal through reorganization: the value of inconsistencies between formal and informal organization,' Organization Science, 20(2), 422-440.

Gulati, R., P. R. Lawrence and P. Puranam (2005), 'Adaptation in vertical relationships: beyond incentive conflict,' Strategic Management Journal, 26(5), 415-440.

Gulley, N. (2001), 'Patterns of innovation: a web-based MATLAB programming contest,' in CHI'01 Extended Abstracts on Human Factors in Computing Systems. ACM, 337-338.

Gulley, N. (2004), 'In praise of tweaking: a wiki-like programming contest,' Interactions, 11(3), 18-23.

Gutwin, C., R. Penner and K. Schneider (2004), 'Group awareness in distributed software development,' in Proceedings of the 2004 ACM conference on Computer Supported Cooperative Work. ACM, 72-81.

Helper, S., J. P. MacDuffie and C. Sabel (2000), 'Pragmatic collaborations: advancing knowledge while controlling opportunism,' Industrial and Corporate Change, 9(3), 443-488.

Herbsleb, J. D., D. J. Paulish and M. Bass (2005), 'Global software development at Siemens: experience from nine projects,' in Proceedings of 27th International Conference on Software Engineering, 2005. IEEE, 524-533.

Herraiz, I., G. Robles, J. J. Amor, T. Romera and J. M. González Barahona (2006), 'The processes of joining in global distributed software projects,' in Proceedings of the 2006 International Workshop on Global Software Development for the Practitioner. ACM, 27-33.

Hoetker, G., A. Swaminathan and W. Mitchell (2007), 'Modularity and the impact of buyer-supplier relationships on the survival of suppliers,' Management Science, 53(2), 178-191.

Howison, J. and K. Crowston (2014), 'Collaboration through open superposition: a theory of the open source way,' MIS Quarterly, $38(1), 29-50$.

Bolici, F., J. Howison and K. Crowston (2009), 'Coordination without discussion? Socio-technical congruence and stigmergy in free and open source software projects,' paper presented at Socio-Technical Congruence Workshop in conjunction with the International Conference on Software Engineering,Vancouver, Canada. Available at http://citeseerx.ist.psu.edu/viewdoc/down load?doi=10.1.1.193.7473\&rep=rep1\&type=pdf.

Jacobides, M. G. (2005), 'Industry change through vertical disintegration: how and why markets emerged in mortgage banking,' Academy of Management Journal, 48(3), 465-498.

Jacobides, M. G. and S. Billinger (2006), 'Designing the boundaries of the firm: from "make, buy, or ally" to the dynamic benefits of vertical architecture,' Organization Science, 17(2), 249-261.

King, A. (1999), 'Retrieving and transferring embodied data: implications for the management of interdependence within organizations,' Management Science, 45(7), 918-935.

Koch, S. and G. Schneider (2002), 'Effort, co-operation and co-ordination in an open source software project: GNOME,' Information Systems Journal, 12(1), 27-42.

Kokshagina, O., E. Boxenbaum and M. Cartel (2015), 'A process of collective bricolage: crafting highly diffusable innovations in contexts of high uncertainty,' paper presented at the 75th Annual Meeting of the Academy of Management. Vancouver, Canada.

Kratzer, J., H. G. Gemünden and C. Lettl (2008), 'Balancing creativity and time efficiency in multi-team R\&D projects: the alignment of formal and informal networks,' R\&D Management, 38(5), 538-549.

Langlois, R. N. and P. L. Robertson (1992), 'Networks and innovation in a modular system: lessons from the microcomputer and stereo component industries,' Research Policy, 21(4), 297-313.

Le, Q. and J. H. Panchal (2012), 'Analysis of the interdependent co-evolution of product structures and community structures using dependency modelling techniques,' Journal of Engineering Design, 23(10-11), 807-828.

Lecocq, X. and B. Demil (2006), 'Strategizing industry structure: the case of open systems in a low-tech industry,' Strategic Management Journal, 27(9), 891-898.

Lee, J. and N. Berente (2012), 'Digital innovation and the division of innovative labor: digital controls in the automotive industry,' Organization Science, 23(5), 1428-1447.

Lo, D., K. M. Frias and M. Ghosh (2012), 'Price formats for branded components in industrial markets: an integration of transaction cost economics and the resource-based view,' Organization Science, 23(5), 1282-1297.

MacCormack, A., C. Baldwin and J. Rusnak (2012), 'Exploring the duality between product and organizational architectures: a test of the “mirroring” hypothesis,' Research Policy, 41(8), 1309-1324.

MacCormack, A., J. Rusnak and C. Y. Baldwin (2006), 'Exploring the structure of complex software designs: an empirical study of open source and proprietary code,' Management Science, 52(7), 1015-1030. (Counted as descriptive open collaborative and normative within-firm.)

Mockus, A., R. T. Fielding and J. Herbsleb (2000), 'A case study of open source software development: the Apache server,' in Proceedings of the 22nd International Conference on Software Engineering. ACM, 263-272.

Moeen, M., D. Somaya and J. T. Mahoney (2013), 'Supply portfolio concentration in outsourced knowledge-based services,' Organization Science, 24(1), 262-279. 
Monteverde, K. (1995), 'Technical dialog as an incentive for vertical integration in the semiconductor industry,' Management Science, 41(10), 1624-1638.

Monteverde, K. and D. J. Teece (1982), 'Supplier switching costs and vertical integration in the automobile industry,' Bell Journal of Economics, 13(1), 206-213.

Morelli, M. D., S. D. Eppinger and R. K. Gulati (1995), 'Predicting technical communication in product development organizations,' IEEE Transactions on Engineering Management, 42(3), 215-222.

Novak, S. and S. D. Eppinger (2001), 'Sourcing by design: product complexity and the supply chain,' Management Science, 47(1), $189-204$.

Parmigiani, A. (2007), 'Why do firms both make and buy? An investigation of concurrent sourcing,' Strategic Management Journal, $28(3), 285-311$.

Parmigiani, A. and W. Mitchell (2009), 'Complementarity, capabilities, and the boundaries of the firm: the impact of within-firm and interfirm expertise on concurrent sourcing of complementary components,' Strategic Management Journal, 30(10), 1065-1091.

Parraguez, P., S. D. Eppinger and A. M. Maier (2015), 'Information flow through stages of complex engineering design projects: a dynamic network analysis approach,' IEEE Transactions on Engineering Management, 62(4), 604-617.

Paulson, J. W., G. Succi and A. Eberlein (2004), 'An empirical study of open-source and closed-source software products,' IEEE Transactions on Software Engineering, 30(4), 246-256.

Puranam, P., H. Singh and S. Chaudhuri (2009), 'Integrating acquired capabilities: when structural integration is (un) necessary,' Organization Science, 20(2), 313-328.

Sahaym, A., H. K. Steensma and M. A. Schilling (2007), 'The influence of information technology on the use of loosely coupled organizational forms: an industry-level analysis,' Organization Science, 18(5), 865-880.

Schilling, M. A. and H. K. Steensma (2001), 'The use of modular organizational forms: an industry-level analysis,' Academy of Management Journal, 44(6), 1149-1168.

Sobrero, M. and S. Schrader (1998), 'Structuring inter-firm relationships: a metaanalytic approach,' Organization Studies, 19(4), 585-615.

Sosa, M. E. (2008), 'A structured approach to predicting and managing technical interactions in software development,' Research in Engineering Design, 19(1), 47-70.

Sosa, M. E. (2014), 'Realizing the need for rework: from task interdependence to social networks,' Production and Operations Management, 23(8), 1312-1331.

Sosa, M. E., S. D. Eppinger and C. M. Rowles (2004), 'The misalignment of product architecture and organizational structure in complex product development,' Management Science, 50(12), 1674-1689.

Sosa, M. E., S. D. Eppinger, M. Pich, D. G. McKendrick and S. K. Stout (2002), 'Factors that influence technical communication in distributed product development: an empirical study in the telecommunications industry,' IEEE Transactions on Engineering Management, 49(1), 45-58.

Sosa, M. E., M. Gargiulo and C. Rowles (2015), 'Can informal communication networks disrupt coordination in new product development projects?’ Organization Science, 26(4), 1059-1078.

Spinellis, D. (2006), 'Global software development in the FreeBSD project,' in Proceedings of the 2006 International Workshop on Global Software Development for the Practitioner. ACM, 73-79.

Srikanth, K. and P. Puranam (2011), 'Integrating distributed work: comparing task design, communication, and tacit coordination mechanisms,' Strategic Management Journal, 32(8), 849-875. (Counted as two descriptive studies, within-firm and across-firm)

Sturgeon, T. J. (2002), 'Modular production networks: a new American model of industrial organization,' Industrial and Corporate Change, 11(3), 451-496.

Tokumaru, N. (2006), 'The organizational evolution of innovative activity in the US semiconductor industry: technological specialization and diversification,' Economics of Innovation and New Technology, 15(6), 591-603.

von Krogh, G., S. Spaeth and K. R. Lakhani (2003), 'Community, joining, and specialization in open source software innovation: a case study,' Research Policy, 32(7), 1217-1241.

Wagstrom, P. and S. Datta (2014), 'Does latitude hurt while longitude kills? Geographical and temporal separation in a large scale software development project,' in Proceedings of the 36th International Conference on Software Engineering. ACM, 199-210.

Zhou, Y. M. (2013), 'Designing for complexity: using divisions and hierarchy to manage complex tasks,' Organization Science, 24(2), 339-355.

\section{References (in Sample) Normative Studies}

Aggarwal, V. A. and B. Wu (2014), 'Organizational constraints to adaptation: intrafirm asymmetry in the locus of coordination,' Organization Science, 26(1), 218-238.

Amrit, C. and J. Van Hillegersberg (2008), 'Detecting coordination problems in collaborative software development environments,' Information Systems Management, 25(1), 57-70. 
Andersen, P. H. (1999), 'Organizing international technological collaboration in subcontractor relationships: an investigation of the knowledge-stickiness problem,' Research Policy, 28(6), 625-642.

Appleyard, M. M., C. Y. Wang, J. A. Liddle and J. Carruthers (2008), 'The innovator's non-dilemma: the case of next-generation lithography,' Managerial and Decision Economics, 29(5), 407-423.

Argyres, N. S. (1999), 'The impact of information technology on coordination: evidence from the B-2 "Stealth" bomber,' Organization Science, 10(2), 162-180.

Bailey, D. E., P. M. Leonardi and S. R. Barley (2012), ‘ The lure of the virtual,' Organization Science, 23(5), $1485-1504$.

Baldwin, C. Y. and K. B. Clark (2000), Design Rules: the Power of Modularity, Vol. 1, Chapter 7. MIT Press: Cambridge, MA. (Chapters 1 and 14 are counted as a descriptive industry study.)

Barlow, J. (2000), 'Innovation and learning in complex offshore construction projects,' Research Policy, 29(7-8), 973-989.

Bonaccorsi, A. and A. Lipparini (1994), 'Strategic partnerships in new product development: an Italian case study,' Journal of Product Innovation Management, 11(2), 134-145.

Brusoni, S. (2005), 'The limits to specialization: problem solving and coordination in 'modular networks', Organization Studies, 26(12), 1885-1907.

Brusoni, S. and A. Prencipe (2011), 'Patterns of modularization: the dynamics of product architecture in complex systems,' European Management Review, 8(2), 67-80.

Brusoni, S., A. Prencipe and K. Pavitt (2001), 'Knowledge specialization, organizational coupling, and the boundaries of the firm: why do firms know more than they make?’ Administrative Science Quarterly, 46(4), 597-621.

Cabigiosu, A., F. Zirpoli and A. Camuffo (2013), 'Modularity, interfaces definition and the integration of external sources of innovation in the automotive industry,' Research Policy, 42(3), 662-675.

Zirpoli, F. and A. Camuffo (2009), 'Product architecture, inter-firm vertical coordination and knowledge partitioning in the auto industry,' European Management Review, 6(4), 250-264.

Cacciatori, E. and M. G. Jacobides (2005), 'The dynamic limits of specialization: vertical integration reconsidered,' Organization Studies, 26(12), 1851-1883.

Cataldo, M., J. D. Herbsleb and K. M. Carley (2008), 'Socio-technical congruence: a framework for assessing the impact of technical and work dependencies on software development productivity,' in Proceedings of the Second ACM-IEEE International Symposium on Empirical Software Engineering and Measurement. ACM, 2-11.

Cataldo, M., P. A. Wagstrom, J. D. Herbsleb and K. M. Carley (2006), 'Identification of coordination requirements: implications for the Design of collaboration and awareness tools,' in Proceedings of the 200620 th Anniversary Conference on Computer Supported Cooperative Work. ACM, 353-362.

Chesbrough, H. W. (2006), Open Innovation: the New Imperative for Creating and Profiting from Technology, Chapter 5. Harvard Business School Press: Boston, MA.

Clark, K. B. (1989), 'Project scope and project performance: the effect of parts strategy and supplier involvement on product development,' Management Science, 35(10), 1247-1263.

Collinson, S. and D. C. Wilson (2006), 'Inertia in Japanese organizations: knowledge management routines and failure to innovate,' Organization Studies, 27(9), 1359-1387.

Colwell, R. P. (2005), The Pentium Chronicles: the People, Passion, and Politics Behind Intel's Landmark Chips (Software Engineering Best Practices). Wiley-IEEE Computer Society Press: Hoboken, NJ.

D'Adderio, L. and N. Pollock (2014), 'Performing modularity: competing rules, performative struggles and the effect of organizational theories on the organization,' Organization Studies, 35(12), 1813-1843.

Dibiaggio, L. (2007), 'Design complexity, vertical disintegration and knowledge organization in the semiconductor industry,' Industrial and Corporate Change, 16(2), 239-267.

Dougherty, D. and D. D. Dunne (2012), 'Digital science and knowledge boundaries in complex innovation,' Organization Science, 23(5), 1467-1484.

Fixson, S. K. and J. K. Park (2008), 'The power of integrality: linkages between product architecture, innovation, and industry structure,' Research Policy, 37(8), 1296-1316.

Garud, R. and K. Munir (2008), 'From transaction to transformation costs: the case of Polaroid's SX-70 camera,' Research Policy, 37(4), 690-705.

Gil, N. and B. S. Tether (2011), 'Project risk management and design flexibility: analysing a case and conditions of complementarity,' Research Policy, 40(3), 415-428.

Gokpinar, B., W. J. Hopp and S. M. Iravani (2010), 'The impact of misalignment of organizational structure and product architecture on quality in complex product development,' Management Science, 56(3), 468-484.

Gomes, P. J. and N. R. Joglekar (2008), 'Linking modularity with problem solving and coordination efforts,' Managerial and Decision Economics, 29(5), 443-457.

Haefliger, S., G. von Krogh and S. Spaeth (2008), 'Code reuse in open source software,' Management Science, 54(1), $180-193$. 
Henderson, R. M. and K. B. Clark (1990), 'Architectural innovation: the reconfiguration of existing product technologies and the failure of established firms,' Administrative Science Quarterly, 35(1), 9-30.

Herbsleb, J. D. and R. E. Grinter (1999), 'Splitting the organization and integrating the code: conway's law revisited,' in Proceedings of the 21st International Conference on Software Engineering. ACM, 85-95.

Herbsleb, J. D. and R. E. Grinter (1999), 'Architectures, coordination, and distance: Conway's law and beyond,' IEEE Software, 16(5), 63-70.

Herbsleb, J. D. and A. Mockus (2003), 'An empirical study of speed and communication in globally distributed software development,' IEEE Transactions on Software Engineering, 29(6), 481-494.

Hoetker, G. (2006), 'Do modular products lead to modular organizations?' Strategic Management Journal, 27(6), 501-518.

Howard, M. and B. Squire (2007), 'Modularization and the impact on supply relationships,' International Journal of Operations and Production Management, 27(11), 1192-1212.

Jacobides, M. G. and C. J. Tae (2015), 'Kingpins, bottlenecks, and value dynamics along a sector,' Organization Science, 26(3), 889-907

Jacobides, M. G., J. P. Macduffie and C. J. Tae (2015), 'Agency, structure, and the dominance of OEMs: change and stability in the automotive sector,' Strategic Management Journal, 37(9), 1942-1967

Kapoor, R. (2013), 'Persistence of integration in the face of specialization: how firms navigated the winds of disintegration and shaped the architecture of the semiconductor industry,' Organization Science, 24(4), 1195-1213.

Kapoor, R. and R. Adner (2012), 'What firms make vs. what they know: how firms' production and knowledge boundaries affect competitive advantage in the face of technological change,' Organization Science, 23(5), 1227-1248.

Kittur, A. and R. E. Kraut (2008), 'Harnessing the wisdom of crowds in wikipedia: quality through coordination,' in Proceedings of the 2008 ACM Conference on Computer Supported Cooperative Work. ACM, 37-46.

Kwan, I., A. Schröter and D. Damian (2011), 'Does socio-technical congruence have an effect on software build success? A study of coordination in a software project,' IEEE Transactions on Software Engineering, 37(3), 307-324.

LaMantia, M. J., Y. Cai, A. D. MacCormack and J. Rusnak (2008), 'Analyzing the evolution of large-scale software systems using design structure matrices and design rule theory: two exploratory cases,' in WICSA 2008 Proceedings of the Seventh Working IEEE/IFIP Conference on Software Architecture, 2008. IEEE, 83-92.

Langner, B. and V. P. Seidel (2009), 'Collaborative concept development using supplier competitions: insights from the automotive industry,' Journal of Engineering and Technology Management, 26(1), 1-14.

Lehnerd, A. P. (1987), 'Revitalizing the manufacture and design of mature global products,' Technology and Global Industry: Companies and Nations in the World Economy, National Academy Press: Washington, DC.

MacCormack, A., J. Rusnak and C. Y. Baldwin (2006), 'Exploring the structure of complex software designs: an empirical study of open source and proprietary code,' Management Science, 52(7), 1015-1030. (Counted as descriptive open collaborative and normative within-firm)

MacDuffie, J. P. (2013), 'Modularity-as-property, modularization-as-process, and 'modularity'-as-frame: lessons from product architecture initiatives in the global automotive industry,' Global Strategy Journal, 3(1), 8-40.

Magnusson, M. and M. Pasche (2014), 'A contingency-based approach to the use of product platforms and modules in new product development,' Journal of Product Innovation Management, 31(3), 434-450.

McIvor, R., P. Humphreys and T. Cadden (2006), 'Supplier involvement in product development in the electronics industry: a case study,' Journal of Engineering and Technology Management, 23(4), 374-397.

Mead, C. and L. Conway (1980), Introduction to VLSI Systems, Vol. 802. Addison-Wesley: Reading, MA.

Mikkola, J. H. (2003). 'Modularity, component outsourcing, and inter-firm learning,' R\&D Management, 33(4), 439-454.

Miller, R., M. Hobday, T. Leroux-Demers and X. Olleros (1995), 'Innovation in complex systems industries: the case of flight simulation,' Industrial and Corporate Change, 4(2), 363-400.

Miozzo, M. and D. Grimshaw (2005), 'Modularity and innovation in knowledge-intensive business services: IT outsourcing in Germany and the UK,' Research Policy, 34(9), 1419-1439.

Mockus, A., R. T. Fielding and J. D. Herbsleb (2002), 'Two case studies of open source software development: Apache and Mozilla,' ACM Transactions on Software Engineering and Methodology (TOSEM), 11(3), 309-346.

O'Sullivan, A. (2006), 'Why tense, unstable, and diverse relations are inherent in co-designing with suppliers: an aerospace case study,' Industrial and Corporate Change, 15(2), 221-250.

Ovaska, P., M. Rossi and P. Marttiin (2003), 'Architecture as a coordination tool in multi-site software development,' Software Process: Improvement and Practice, 8(4), 233-247.

Park, J. K. and Y. K. Ro (2013), 'Product architectures and sourcing decisions their impact on performance,' Journal of Management, 39(3), 814-846.

Prencipe, A. (1997), 'Technological competencies and product's evolutionary dynamics a case study from the aero-engine industry,' Research Policy, 25(8), 1261-1276. 
Prencipe, A. (2000), 'Breadth and depth of technological capabilities in CoPS: the case of the aircraft engine control system,' Research Policy, 29(7), 895-911.

Ro, Y. K., J. K. Liker and S. K. Fixson (2007), 'Modularity as a strategy for supply chain coordination: the case of US auto,' IEEE Transactions on Engineering Management, 54(1), 172-189.

Rusovan, S., M. Lawford and D. Parnas (2005), 'Open source software development: future or fad,' Perspectives on Free and Open Source Software. MIT Press: Cambridge, MA, 107-121.

Sako, M. (2004) 'Supplier development at Honda, Nissan and Toyota: comparative case studies of organizational capability enhancement,' Industrial and Corporate Change, 13(2), 281-308.

Sanderson, S. and M. Uzumeri (1995), 'Managing product families: the case of the Sony Walkman,' Research Policy, 24(5), 761-782.

Scott, J. E. (2000), 'Facilitating interorganizational learning with information technology,' Journal of Management Information Systems, 17(2), 81-113.

Sheffer, D. A. (2011), Innovation in Modular Industries: Implementing Energy-Efficient Innovations in US Buildings. Unpublished Ph.D thesis, Stanford University. Available at http://purl.standford.edu/rq526jy0504.

Sheffer, D. A. and R. E. Levitt (2010), 'The diffusion of energy saving technologies in the building industry: structural barriers and possible solutions,' Collaboratory for Research on Global Projects. Working Paper, 59. Available at https://gpc-stanford-edu.ezpprod1.hul.harvard.edu/sites/default/files/wp059_0.pdf.

Shibata, T., M. Yano and F. Kodama (2005), 'Empirical analysis of evolution of product architecture: FANUC numerical controllers from 1962 to 1997,' Research Policy, 34(1), 13-31.

Sobrero, M. and E. B. Roberts (2002), 'The trade-off between efficiency and learning in interorganizational relationships for product development,' Management Science, 47(4), 493-511.

Sobrero, M. and E. B. Roberts (2002), 'Strategic management of supplier-manufacturer relations in new product development,' Research Policy, 31(1), 159-182.

Snow, C. C., Ø. D. Fjeldstad, C. Lettl and R. E. Miles (2011), 'Organizing continuous product development and commercialization: the collaborative community of firms model, Journal of Product Innovation Management, 28(1), 3-16.

Staudenmayer, N., M. Tripsas and C. L. Tucci (2005), 'Interfirm modularity and its implications for product development,' Journal of Product Innovation Management, 22(4), 303-321.

Takeishi, A. (2001), 'Bridging inter- and intra- firm boundaries: management of supplier involvement in automobile product development,' Strategic Management Journal, 22(5), 403-433.

Takeishi, A. (2002), 'Knowledge partitioning in the interfirm division of labor: the case of automotive product development,' Organization Science, 13(3), 321-338.

Tang, C. S., J. D. Zimmerman and J. I. Nelson (2009), 'Managing new product development and supply chain risks: the Boeing 787 case,' Supply Chain Forum: An International Journal, 10(2), 74-86.

Tiwana, A. (2008a), 'Does technological modularity substitute for control? A study of alliance performance in software outsourcing,' Strategic Management Journal, 29(7), 769-780.

Tiwana, A. (2008b), 'Does interfirm modularity complement ignorance? A field study of software outsourcing alliances,' Strategic Management Journal, 29(11), 1241-1252.

Tuertscher, P., R. Garud and A. Kumaraswamy (2014), 'Justification and interlaced knowledge at ATLAS, CERN,' Organization Science, 25(6), 1579-1608.

Wüllenweber, K., D. Beimborn, T. Weitzel and W. König (2008), 'The impact of process standardization on business process outsourcing success,' Information Systems Frontiers, 10(2), 211-224.

Zhou, Y. M. and X. Wan (2012), The bottleneck: product variety and coordination failures at A Major Soft Drink Bottling Company. Available at http://cn.ckgsb.com/ (accessed 12 July 2015). 